\title{
Tracing Molecular Properties Throughout Evolution: A Chemoinformatic Approach.
}

\section{Marcelo Otero ${ }^{\mathrm{a}, \mathrm{b}}$, Silvina N. Sarnoc, Sofía L. Acebedod,e, Javier A. Ramírez ${ }^{\mathrm{d}, e *}$.}

aUniversidad de Buenos Aires. Facultad de Ciencias Exactas y Naturales. Departamento de Física. Buenos Aires, Argentina.

buniversidad de Buenos Aires. CONICET. Instituto de Física de Buenos Aires (IFIBA). Buenos Aires, Argentina.

¿Escuela de Ciencia y Tecnología, Universidad Nacional de San Martín, Martín de Irigoyen 3100, 1650, San Martín, Provincia de Buenos Aires, Argentina.

dUniversidad de Buenos Aires. Facultad de Ciencias Exactas y Naturales. Departamento de Química Orgánica. Buenos Aires, Argentina.

eUniversidad de Buenos Aires. CONICET. Unidad de Microanálisis y Métodos Físicos Aplicados a Química Orgánica (UMYMFOR). Buenos Aires, Argentina.

* Corresponding author. E-mail: jar@qo.fcen.uba.ar. Tel: +541145763385 


\section{ABSTRACT}

Evolution of metabolism is a longstanding yet unresolved question, and several hypotheses were proposed to address this complex process from a Darwinian point of view. Modern statistical bioinformatic approaches targeted to the comparative analysis of genomes are being used to detect signatures of natural selection at the gene and population level, as an attempt to understand the origin of primordial metabolism and its expansion. These studies, however, are still mainly centered on genes and the proteins they encode, somehow neglecting the small organic chemicals that support life processes. In this work, we selected steroids as an ancient family of metabolites widely distributed in all eukaryotes and applied unsupervised machine learning techniques to reveal the traits that natural selection has imprinted on molecular properties throughout the evolutionary process. Our results clearly show that sterols, the primal steroids that first appeared, have more conserved properties and that, from then on, more complex compounds with increasingly diverse properties have emerged, suggesting that chemical diversification parallels the expansion of biological complexity. In a wider context, these findings highlight the worth of chemoinformatic approaches to a better understanding the evolution of metabolism.

\section{INTRODUCTION}

Every living organism is a rich source of organic small molecules with a wide range of chemical structures. This chemical diversity originates from the activity of large and numerous families of enzymes that operate in highly branched metabolic pathways. ${ }^{1}$ Although we do not know how and when these pathways originated, several and sometimes opposed models which try to 
explain the evolution of metabolism were developed ${ }^{2}$, models that have recently come under scrutiny thanks to the statistical analysis of the genomes of a growing number of species. ${ }^{3}$

Nevertheless, most of these hypotheses are focused on the evolution of the metabolic enzymes rather than the metabolites they produce. In this sense, a little discussed albeit intriguing model is that of Firn and Jones, who pose an alternative evolutionary framework. ${ }^{4,5}$ The basic idea behind their model is that natural selection acts on the physicochemical properties of the metabolites rather than on the genes encoding the enzymes that produce them. Thus, if a mutation leads to an enzyme able to synthetize a new molecule having properties that enhance the fitness of the organism, then selection will favour the retention of individuals possessing such variant relative to those that do not, which in turn put a selective pressure on the involved enzymes themselves.

Thus, if this hypothesis holds true, it would be possible to find traces that natural selection has imprinted on the properties of metabolites. In order to perform an exploratory test of this ideas, we decided to select a widely distributed family of metabolites, with an ancient origin and whose biosynthetic relationships are well known. In this sense, steroids emerged as an appealing set of compounds, as they have essential biological functions in all eukaryotes. Moreover, in the last decades a wealth of information has been gathered about the underlying metabolic pathways that generate them, which revealed several conserved mechanisms across different taxa.

Steroid biosynthesis comprises essentially three phases. In the first one, squalene, the alicyclic triterpene which is the common precursor of steroids both in animals and plants, is oxidized by the enzyme oxidosqualene cyclase, suffering a domino-like series of ring-closing reactions with the concomitant migration of methyl groups leading to lanosterol in animals and fungi, or 
cycloartenol in plants. ${ }^{6}$ This is an ancient conserved pathway: nowadays, the most widely accepted hypothesis is that sterols may have evolved in eukaryotes as an adaptive response to the sharp rise in atmospheric oxygen ${ }^{7}$ in early Earth about 2.3 billion years ago ${ }^{8,9}$, since steroids limit oxygen diffusion across cell membranes in eukaryotes, thus controlling the intracellular levels of reactive oxygen species. ${ }^{10-13}$

Afterwards, the tetracyclic carbon skeleton is modified mainly by oxidative enzymatic transformations which are phylum-dependent: lanosterol is converted into cholesterol through a nineteen-step pathway in animals, whereas a very similar set of transformations leads to ergosterol in fungi. Alternatively, cycloartenol is converted into the major plant steroids campesterol and sitosterol. ${ }^{14,15}$ All these sterols share the property of being able to interact with phospholipids within biological membranes modifying their fluidity, permeability and other biophysical features, which turn these steroids into essential players in living processes.

From this point on, the metabolic pathways diverge in increasingly complex ways. Apart from being fundamental components of the biomembranes, the aforementioned steroids may serve as precursors of a series of derivatives with more specialized biological functions. In this second biosynthetic phase, cholesterol is transformed into more oxidized compounds such as dafachronic acids in nematodes ${ }^{16}$, ecdysteroids in arthropods ${ }^{17-19}$, and oxysterols and bile acids in vertebrates ${ }^{20}$. These metabolites usually serve as signaling molecules that were essential to evolution of multicellular animals, and recent evidence suggests that the necessary biosynthetic enzymatic machinery first apperared 700 million years ago and diversified for the next 400 millions years. ${ }^{21}$ In vertebrates, additional oxidative transformations may lead to the cleavage of the side chain of cholesterol to give all steroid hormones, including adrenal gland hormones and sex hormones such as estrogens and androgens. ${ }^{21}$ On the other hand, sitosterol and campesterol 
also serve as precursors for the biosynthesis of brassinosteroids, polyoxygenated metabolites with hormonal action in most vascular plants and some ferns and mosses (Figure 1). 


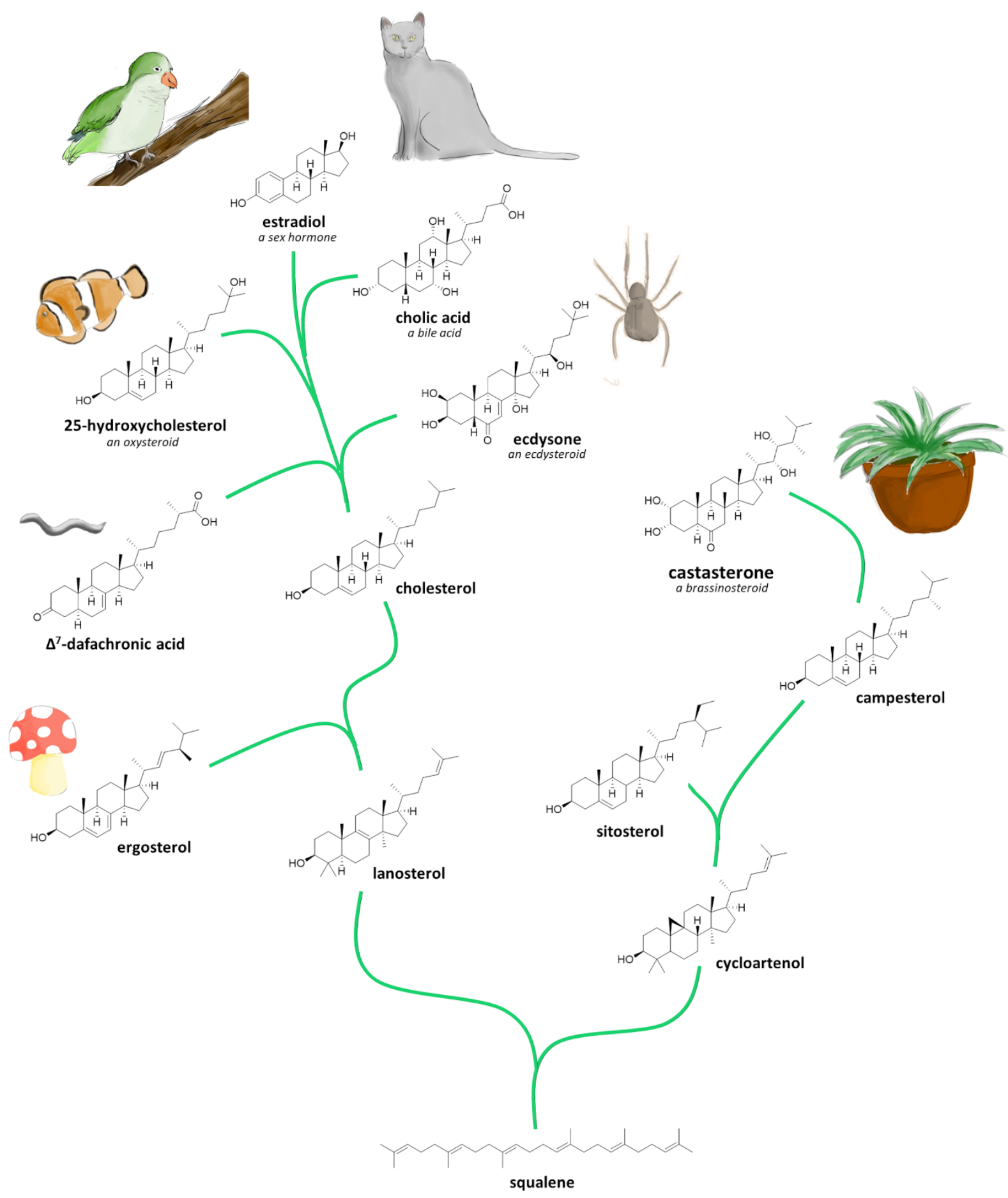

Figure 1. Diversification of Steroids from squalene.

Of note, despite the differences between these phylum-dependent steroidal metabolic pathways, it is clear that all members of this ancient family of polyhydroxylated lipids are synthesized via a 
cascade of highly conserved oxygen-dependent cytochrome P450 enzymes, which suggests that these pathways have evolved from a common unicellular ancestor. ${ }^{22-24}$

In some species, however, especially plants and marine invertebrates but also amphibians, a third phase may be present in which further transformations, which Diarey Tianero et al. coined as "diversity generating pathways", lead to a plethora of structurally complex steroids which are believed to have an ecological function, serving as a defensive chemical barrier against pathogens or predators ${ }^{25}$, and arose about 125 million years ago, as ecological networks became more intricated. ${ }^{26}$ Several thousands of such steroids are currently known, although their biosynthetic origin remains to be established in most cases.

Given the aforementioned facts, steroids reveal a very suitable family of metabolites for performing a comparative analysis of their properties by using chemoinformatic tools in order to unravel the likely connection between structural properties of small organic biogenic molecules and metabolic evolution.

\section{RESULTS AND DISCUSSION}

A database of natural steroids was curated and annotated accordingly to the biosynthetic phases to which they belong. The first group comprised membrane sterols found in animals, fungi, and plants, such as cholesterol, ergosterol and sitosterol, and their biosynthetic precursors from squalene (S-steroids). The second group included steroids which have endogenous signaling (hormonal) roles, along with their biosynthetic precursors (H-steroids), whereas the third group (secondary metabolites or M-steroids) is a representative random sample of steroids from all phyla that can be classified as secondary metabolites. In total, the database included 479 
compounds: 39 S-steroids (S001 to S0039), 159 H-steroids (H001 to H159) and 281 M-steroids (M001 to M281).

Sixty-four molecular descriptors were calculated for every compound. These molecular descriptors were selected in order to cover a wide range of molecular properties such as elemental analysis, hydrogen bond donor and acceptor, partitioning and distribution, global topological indices based on 2D-molecular graphs, geometric, ring and chain, and molecular complexity properties (for a list of the selected descriptors, see the Supplementary Information). In this context, each steroid in the database could be considered as a point in a 64-dimensional chemical space defined by the selected molecular descriptors. Thus, the position of a given compound in such space reflects its physicochemical properties. Given our interest in analyzing how the members of the three families, classified according to their biosynthetic relationship, are distributed in this chemical space, we performed a Principal Component Analysis (PCA), a multivariate statistical method for variable reduction. This method consists in the creation of a new set of variables -called principal components- that are linear combinations of the original variables (orthogonal to each other), which allows the visualization of multidimensional data by using 2D-scatter plots with minimal loss of information of the original set of variables. ${ }^{27}$

Through this analysis, we found that the first four principal components (PC1, PC2, PC3 and PC4) retain $43.1 \%, 13.9 \%, 9.9 \%$ and $9.5 \%$ of the total variance, respectively. It is remarkable to note that only four of the sixty-four principal components can explain $76.4 \%$ of the total variance of the original dataset (for further information, see the scree plot in the Supplementary Information). 
Moreover, it is possible to understand how each original descriptor contributes to the new principal components. For example, PC1 is related mainly to molecular size, volume, and weight, whereas PC2 is related principally to planarity and molecular complexity. On the other hand, PC3 and PC4 share contributions from complexity, hydrophobicity, polarity, and hydrogen bond donor-acceptor properties (for more details, see the contribution plots in the Supplementary Information).

Figure 2 shows the PCA 2D-scatter plots of the four principal components, ordered from highest to lowest percentage of explained variances: (a) PC2 vs. PC1 (57.0\%), (b) PC3 vs. PC1 (53.0\%), (c) PC4 vs. PC1 (52.6\%), (d) PC3 vs. PC2 (23.8\%), (e) PC4 vs. PC2 (23.4\%) and (f) PC4 vs. PC3 (19.4\%). The dots correspond to the position of the compounds in the chemical space defined by the principal components, and the colored ellipses correspond to the concentration ellipses of 0.95 level. 

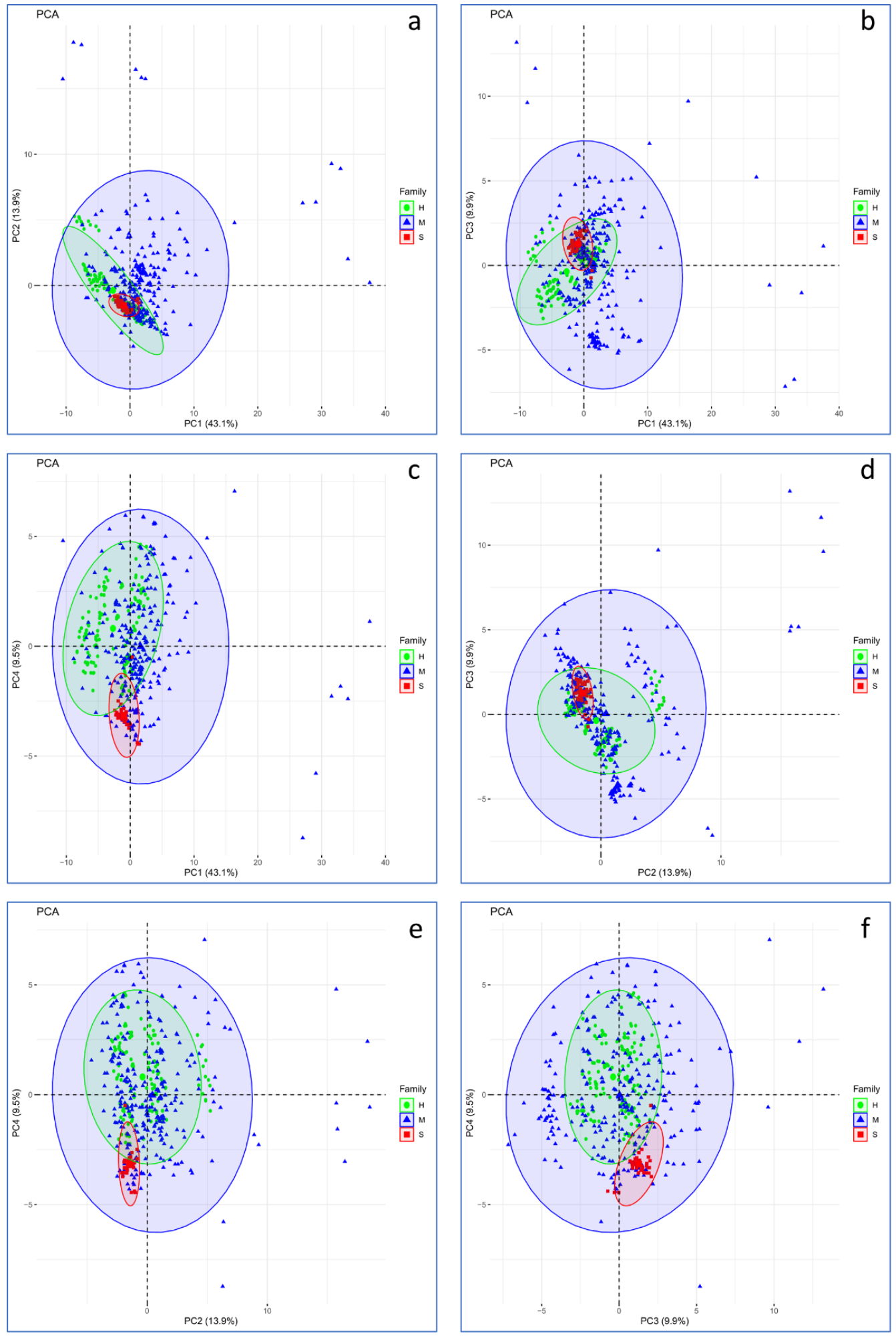

Figure 2: PCA 2D-scatter plots ordered according to the percentage of explained variances: (a) PC2-PC1 (57.0\%), (b) PC3-PC1 (53.0\%), (c) PC4-PC1 (52.6\%), (d) PC3-PC2 (23.8\%), (e) PC4-PC2 (23.4\%) and (f) PC4-PC3 (19.4\%). The dots correspond to the position of the compounds in the chemical space defined by the pair of principal components and 
the colored ellipses correspond to the concentration ellipses of 0.95 level (the 0.95 concentration ellipse is expected to enclose $95 \%$ of the data points, according to a bivariate normal distribution).

The PCA 2D-scatter plots show that S-steroids, H-steroids, and M-steroids are not equally distributed across the chemical space. A visual inspection shows that S-steroids occupy a restricted region, which means that they are more similar to one another, in contrast to $\mathrm{H}$ steroids, which span through a wider area, thus showing greater diversity. Moreover, M-steroids show the largest variability in their properties. This variability can be properly quantified by calculating the standard deviations (SD) in every component, which are depicted in Figure 3.

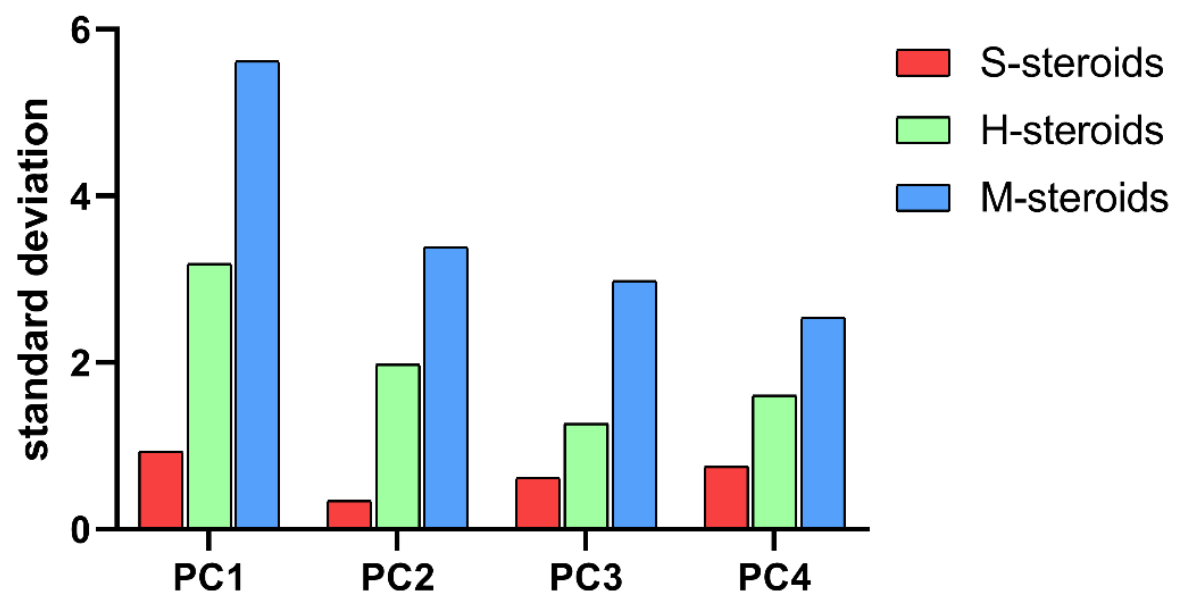

Figure 3: Standard deviations of principal components PC1, PC2, PC3 and PC4 for the three families of compounds.

One of the long-standing models aimed to explain the evolution of biosynthetic pathways is the Granick hypothesis ${ }^{28}$, whose central assumption is that the biosynthesis of many end-products could be explained by the forward evolution from relatively simple precursors. A prediction of the 
model is that the simpler compounds predated the complex ones ${ }^{3}$, a trend that clearly emerges from our results.

On the other hand, Figure 2 shows that the three families do not only differ in variability, but also in the relative position within the chemical space, which means that they have distinctive mean properties. Aiming to gain more insight into these differences, we constructed box-and-whisker plots for the 64 molecular descriptors (see Supplementary Information). Figure 4 shows the boxplots of eight selected properties and descriptors which highlight the differences and similarities among $\mathrm{S}-, \mathrm{H}$ - and $\mathrm{M}$-steroids.

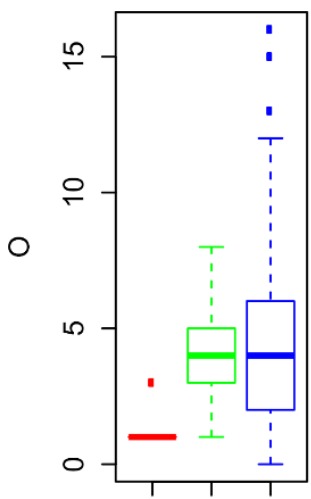

$S \quad H \quad M$

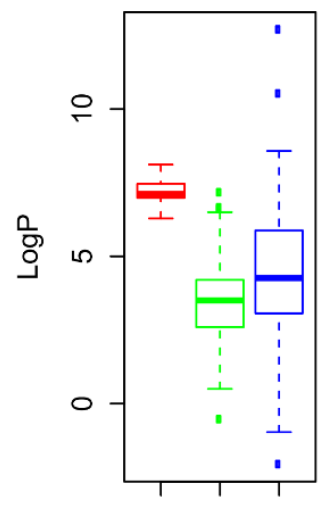

$S \quad H \quad M$

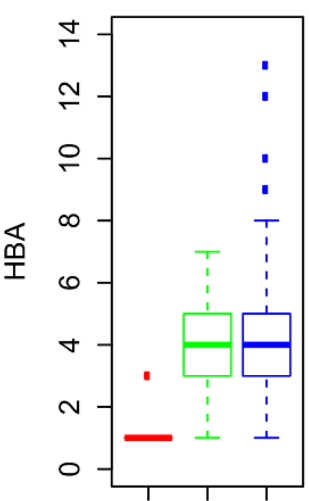

$\mathrm{S} \quad \mathrm{H} \quad \mathrm{M}$

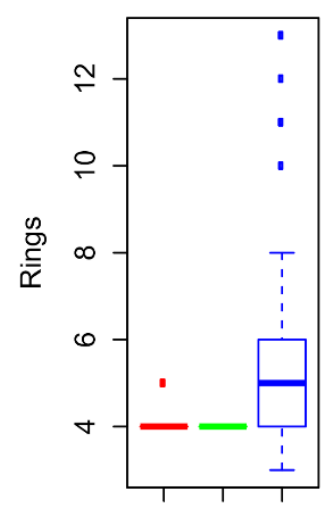

S $\mathrm{H} \quad \mathrm{M}$

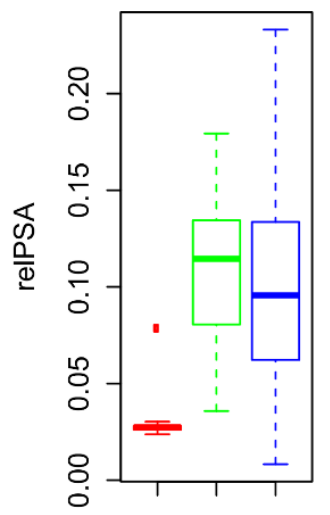

$\mathrm{S} \quad \mathrm{H} \quad \mathrm{M}$

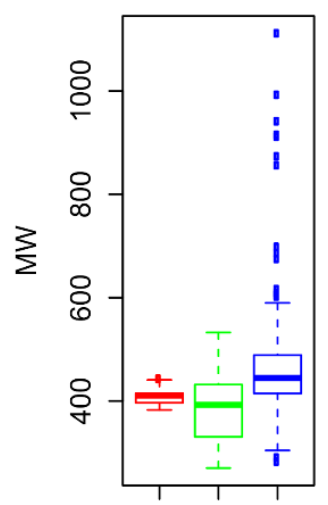

$S \quad H \quad M$

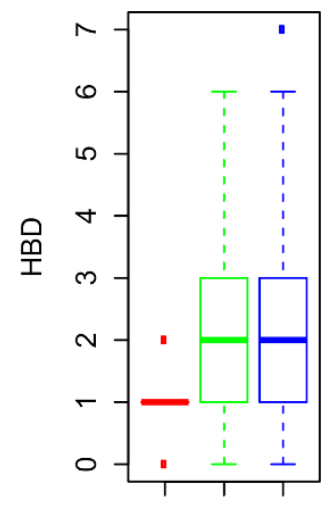

$S \quad H \quad M$

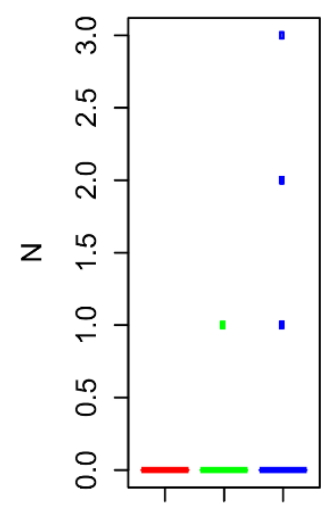

S $\mathrm{H} \quad \mathrm{M}$

Figure 4: Comparative box-and-whisker plots for S-, $\mathrm{H}$ - and $\mathrm{M}$-steroids illustrating the distribution of values for descriptors discussed in the text. 
At first sight, the narrower width of all the boxplots belonging to the S-steroids shows that their physicochemical properties are very similar. This restricted variability, which is in line with the lower standard deviations found in the PCA analysis, also translates into common biological roles. In this sense, it is known, for example, that replacing ergosterol in S. cerevisiae with the plant sterol campesterol or the animal sterol cholesterol leads to viable cells. Souza et al. suggest that some basic functions of sterols linked to their properties, such as the ability to form membrane microdomains, have been retained along evolution, leaving little room for major changes in their structures. ${ }^{29}$ On the other hand, S-steroids have a low median value of oxygen atoms (one per molecule) when compared to $\mathrm{H}$ - and $\mathrm{M}$-steroids, which have a median value of four per molecule, probably reflecting their appearance in an oxygen-rich atmosphere. ${ }^{24}$

Other distinctive feature of S-steroids, which is directly related to oxygen content, is their much higher lipophilicity, as evidenced, for example, by their logP median values (7.1 vs. 3.5 for $\mathrm{H}$ steroids and 4.3 for M-steroids). Likewise, the median relative polar surface area (relPSA, defined as the theoretical polar area normalized by the Van der Waals surface area) increases from 0.027 to 0.114 and 0.096 for S-, $\mathrm{H}$ - and $\mathrm{M}$ - steroids, respectively.

As stated before, the oxidation products of cholesterol and other membrane sterols have been selected by nature to act as signalling molecules, those which we encompassed as $\mathrm{H}$-steroids. These molecules allowed multicellular organisms to respond to environmental stimuli and regulate their homeostasis, development, and reproduction. Evidence suggests that ancient oxygen-dependent cytochrome P450 enzymes, whose functions were to hydroxylate lipophilic xenobiotics ${ }^{30}$, also oxidated membrane sterols to yield polyoxigenated steroids able both to 
traverse lipidic membranes and to act as ligands of receptors, a common feature of all steroid hormones. ${ }^{22}$ This increasing number of oxygenated moieties improved binding ability through hydrogen bond interactions: the median numbers of hydrogen bond donors (HBD) and acceptors (HBA) rise from one in S-steroids to two and four in H-steroids, respectively, as shown in Figure 4. In some species, $\mathrm{S}$-steroids and $\mathrm{H}$-steroids serve as intermediates for the biosynthesis of secondary metabolites (M-steroids) in which the steroidal skeleton may be expanded from the 6 6-6-5 tetracyclic framework to more complex polycyclic systems. The new rings can either be fussed to the parent skeleton (e.g. in tomatidine and diosgenin) or as substituents (e.g. digitoxigenin). In fact, the median value of the number of rings in M-steroids is five for the database analyzed in this work, but contains compounds with up to thirteen rings, generated by more radical transformations such as dimerizations, which also explain the presence of high molecular weight compounds (e.g. cephalostatins) among M-steroids (Chart 1). 

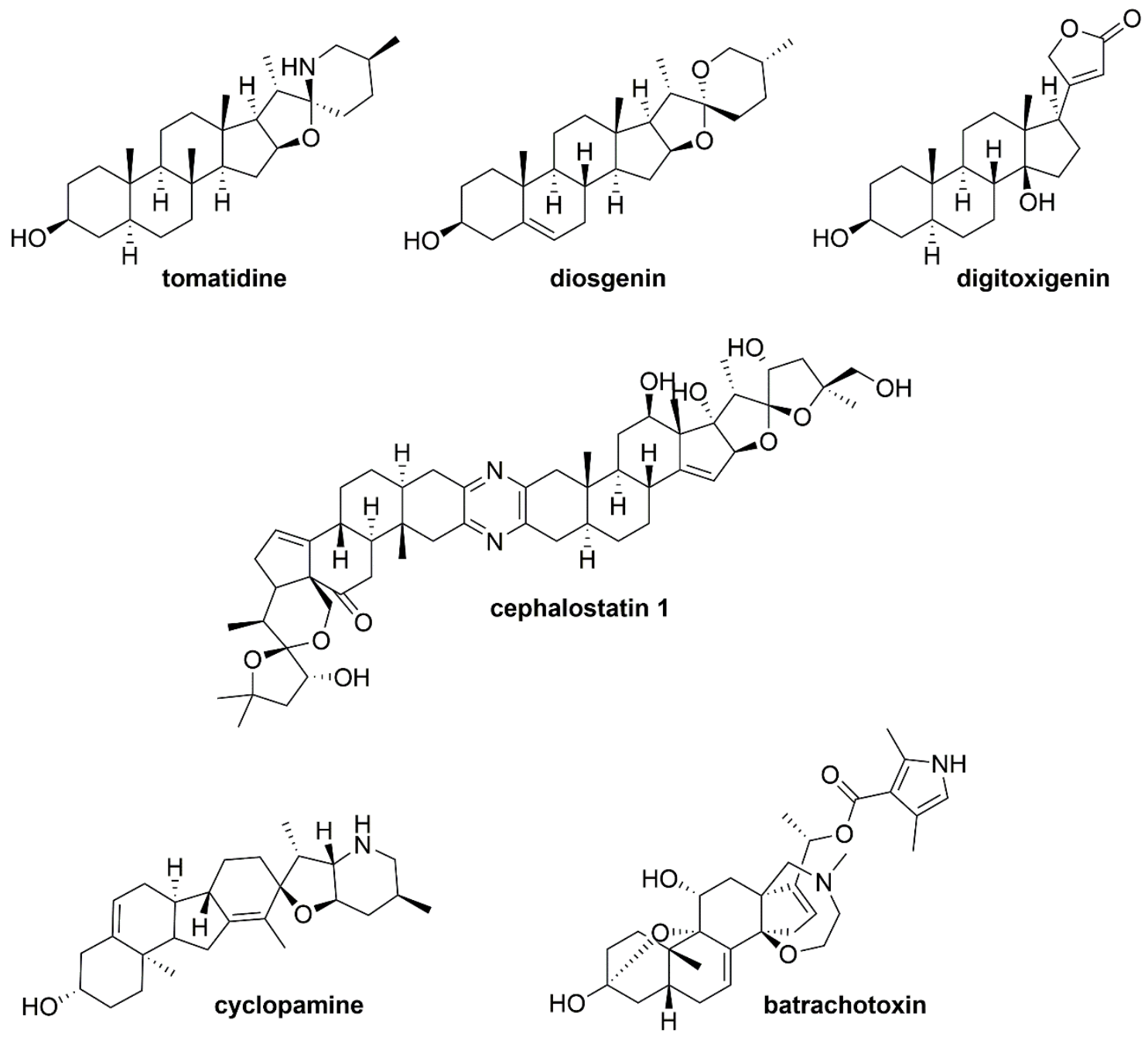

Chart 1. Some representative M-steroids.

Worth pointing out, natural steroids are not rich in nitrogen when compared to other natural products, which may reach values of sixty $\mathrm{N}$ atoms per molecule. ${ }^{31} \mathrm{~S}$-steroids lack nitrogen atoms, whereas the only $\mathrm{N}$-containing $\mathrm{H}$-steroids are bile acids conjugated with amino acids (glycochenodeoxycholic, glycocholic, taurocholic and taurochenodeoxycholic acids). In agreement, our database of $281 \mathrm{M}$-steroids contains steroids having three $\mathrm{N}$ atoms at most.

M-steroids are natural products that do not seem to have an endogenous signaling function in its source organism, but usually serve as a defensive mechanism against a wide range of pathogens 
and predators. For example, the well-studied steroidal alkaloid cyclopamine, produced by Veratrum californicum, causes fatal birth defects when cattle feed upon this plant by binding to the protein Smoothened, thus disrupting the Sonic hedgehog pathway. ${ }^{32}$ Other examples of polycyclic nitrogenated steroids include batrachotoxin, a neurotoxic compound acting on sodium ion channels which is found in frogs of the genus Phyllobates ${ }^{33}$ (Chart 1). Despite their structural diversity, M-steroids share the common feature of being more complex and diverse than the steroids from which they derive, which is reflected by the wider boxplots and the presence of many outliers for the relevant molecular descriptors. In this sense, it is interesting to recall that according to Firn and Jones evolution has favoured mutations leading to metabolic traits that enhanced chemical diversity generation, as the more new compounds are made in an organism after mutation, the greater the chances of any one of these chemicals possessing useful properties that could enhance the fitness of the producer. ${ }^{34}$ In some sense, the diversity oriented synthesis strategies developed by chemists for drug discovery campaigns somehow mimic nature.

Whereas PCA is best suited to grasp the distribution of a given group of compounds in the chemical space, a cluster analysis can provide a deeper insight into the similarity of the members of such group by splitting them in clusters of molecules with related properties. Thus, we conducted a Hierarchical Cluster Analysis (HCA) of the database with the Ward's minimum variance method ${ }^{27}$ using the same 64 molecular descriptors. We visualized the HCA results through a circular dendrogram (Figure 5), in which the alphanumeric codes of S-, $\mathrm{H}$ - and $\mathrm{M}$ steroids are colored in red, green, and blue, respectively. 


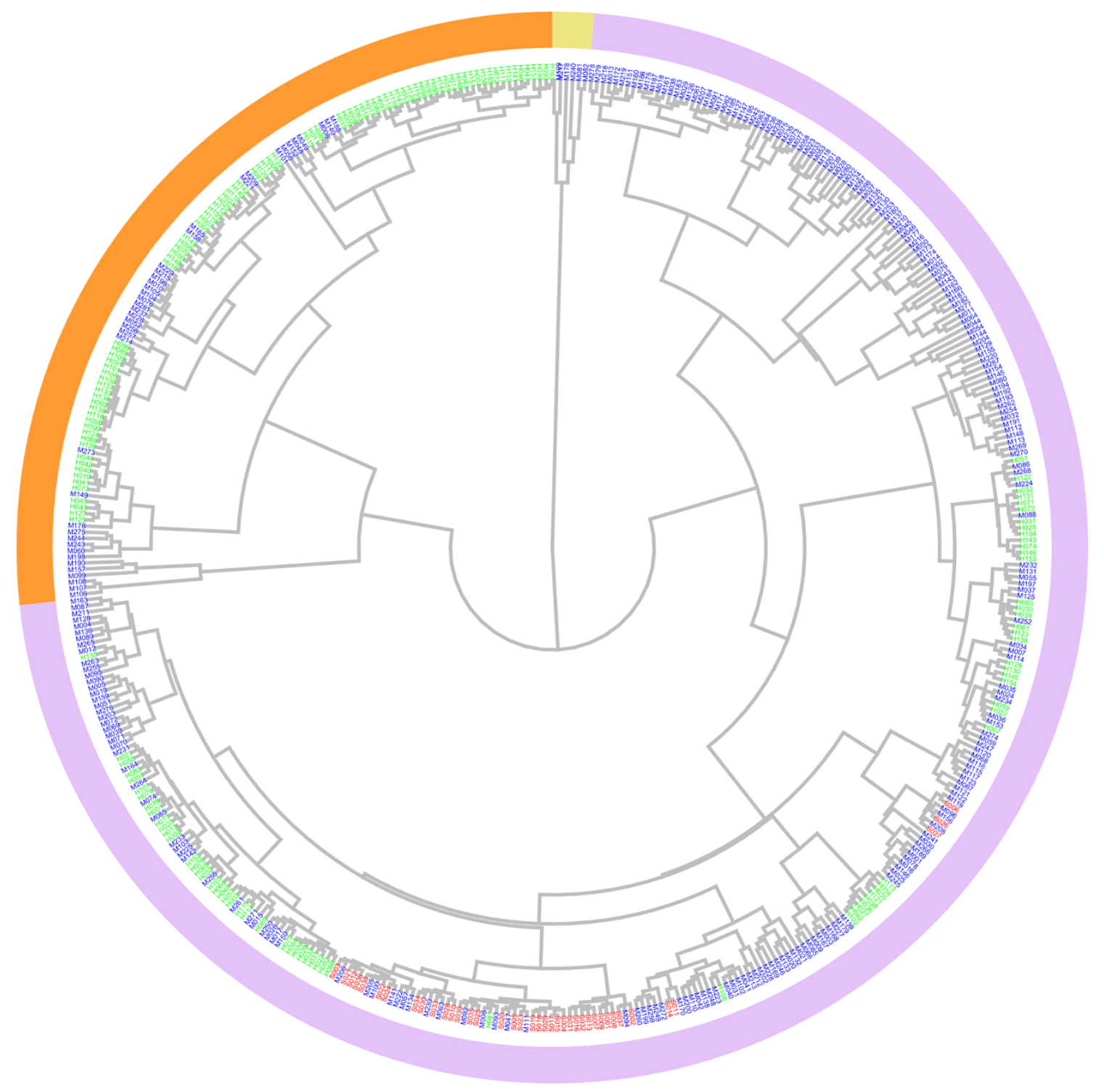

Figure 5: Circular dendrogram of S-steroids (red), H-steroids (green) and M-steroids (blue). The three principal clusters are colored in yellow, orange and violet.

At a glance, we noticed the presence of a cluster (yellow) containing only six members, all of them being M-steroids corresponding to high molecular weight outliers in the Mw boxplot of Figure 4. The rest of the steroids of the database splits into two main clusters (orange and violet). A more detailed inspection reveals that the orange one contains only $\mathrm{H}$ - and $\mathrm{M}$-steroids. Interestingly, every $\mathrm{H}$-steroid of this cluster has a vertebrate origin; moreover, a more detailed analysis shows 
that these vertebrate steroids seem to be also divided in sub-clusters according to their biological role such as sexual hormones and bile acids.

Finally, the largest violet cluster shows the greater diversity, containing most of the M-steroids, all the sterols and their precursors (S-steroids) and all the $\mathrm{H}$-steroids from invertebrate animals and plants, along with a small group of vertebrate $\mathrm{H}$-steroids such as oxysterols. These $\mathrm{H}$-steroids are not randomly mixed but also seem to be distributed in sub-clusters according to phylum and biological function, like the $\mathrm{H}$-steroids belonging to the orange cluster.

At this point, it is clear that an HCA based on comparing simple structural and physicochemical descriptors calculated from the 2D-structures of the database was able to cluster the set of $\mathrm{H}$ steroids into groups containing biologically related compounds. This intriguing fact led us to perform a further HCA focusing exclusively on the H-steroids, which was also depicted as a circular dendrogram (Figure 6a). This analysis confirmed a significant correlation between the biological role of the compounds and the internal structure of the dendrogram. In this sense, a clockwise inspection around the graphic allows to identify nine distinctive clusters, most of them related to different biological functions. For example, the dark green and light blue clusters only contain estrogens and ecdysteroids, respectively.

To dig deeper into these noteworthy results, we clustered the same set of compounds using the k-means method, an alternative non-hierarchical unsupervised machine learning technique in which the number of clusters $(k)$ is defined a priori. ${ }^{35}$ Figure $6 \mathrm{~b}$ consistently shows that when the analysis is performed for $k=9$, the resulting clusters are identical to the clusters found in the HCA.

As a most noticeable result, estrogens do not only conform, as seen in the dendrogram, a defined cluster (cluster \#1), but also lie far from the rest of the H-steroids in the chemical space, probably 
due to the presence of the aromatic ring, a unique structural feature found only in these steroidal hormones (e.g. estrone in Chart 2).

Ecdysteroids, the moulting steroidal hormones in arthropods, also constitute a separate cluster (cluster \#5). In contrast, plant hormones brassinosteroids are split in two different clusters (clusters \#6 and \#7). A detailed analysis shows that cluster \#7 consists of brassinosteroids having a six-membered B ring (such as dolichosterone in Chart 2), while brassinosteroids in cluster \#6 bear a 7-oxalactone functionality in ring B (e.g. brassinolide). Although ecdysteroids and brassinosteroids are hormones of very distant phylogenetic organisms ${ }^{23}$, they are usually considered structurally very similar families: for example, ponasterone A (Chart 2) has an A ring hydroxylated at carbons 2 and 3, a 6-keto group and also a dihydroxylated side chain, common features also present in many brassinosteroids. Even when they are close in the chemical space, the analysis performed in this work found enough differences between these families of compounds to clearly separate ecdysteroids from brassinosteroids into different clusters.

In addition, bile acids also split into two different clusters (clusters \#4 and \#8), with the smallest one (cluster \#8) containing four bile acids which are conjugated to amino acids. Finally, cluster \#9 comprises most of the androgens and progestagens (such as androsterone and pregnenolone) and cluster \#3 includes most of the corticosteroids (e.g. cortisone). 

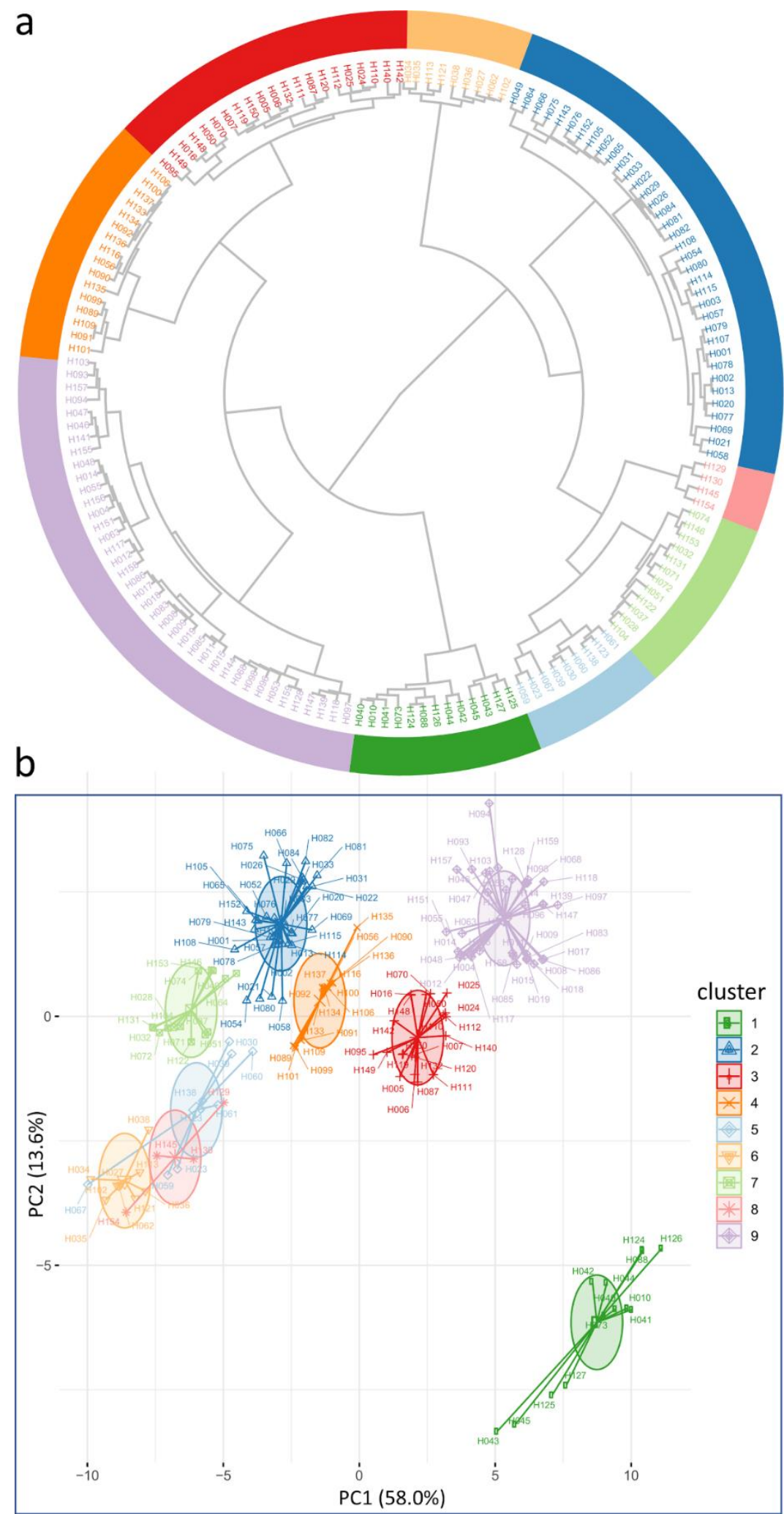

Figure 6: (a) Circular dendrogram of the H-steroids with the nine principal clusters. (b) PCA cluster plot with nine clusters obtained with k-means clustering method. The same coloring for each cluster was used in both graphics. 

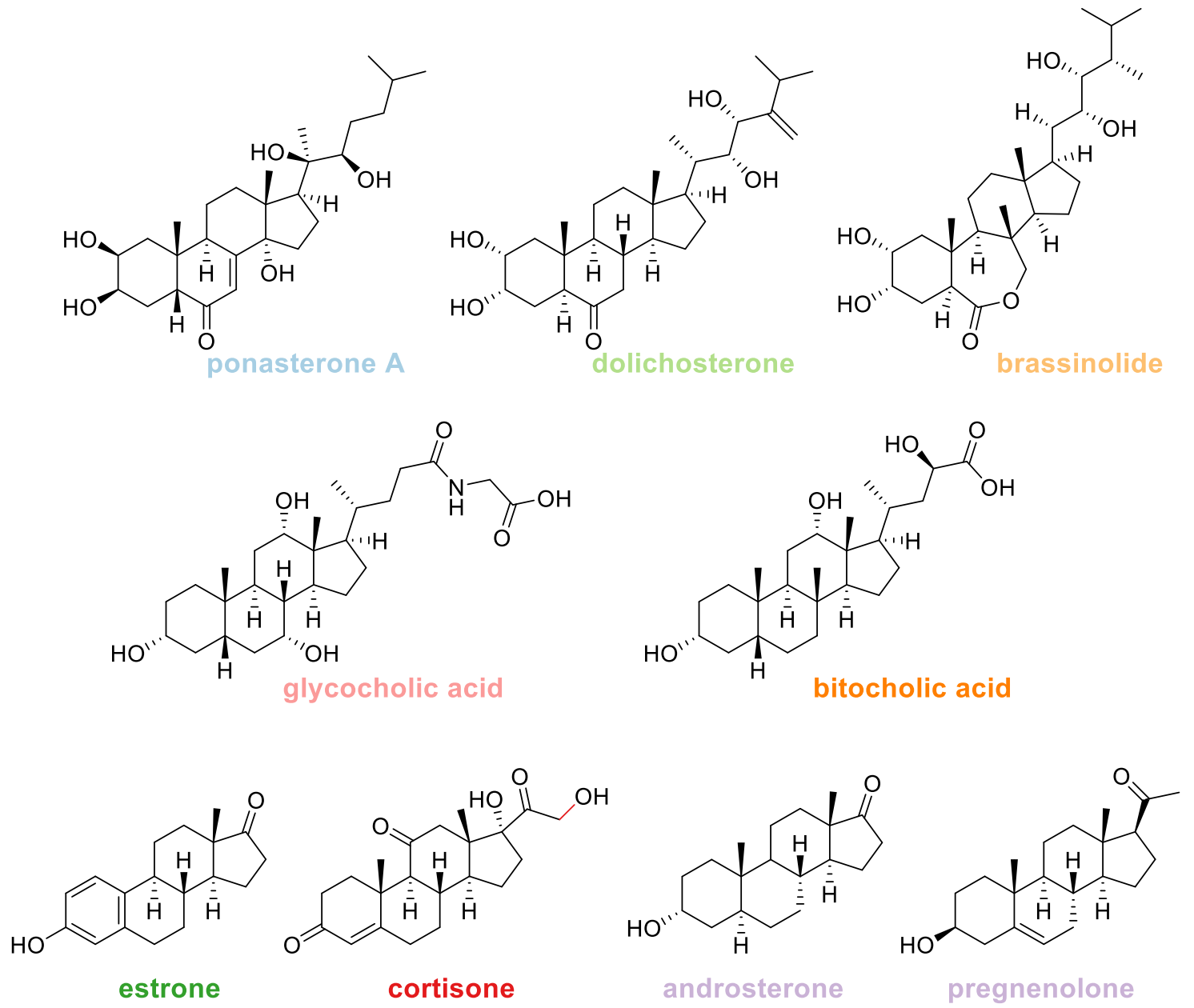

Chart 2. Representative members of clusters \#1 to \#9.

Even if the remaining cluster \#2 cannot be easily associated to a defined biological role, a biosynthetic pathway map (Figure 7) in which $\mathrm{H}$-steroids were colored according to the cluster they belong revealed that compounds of cluster \#2 share a common relative position within the biosynthetic map, as they are early biosynthetic intermediates closer to the S-steroids than the rest of the H-steroids. 


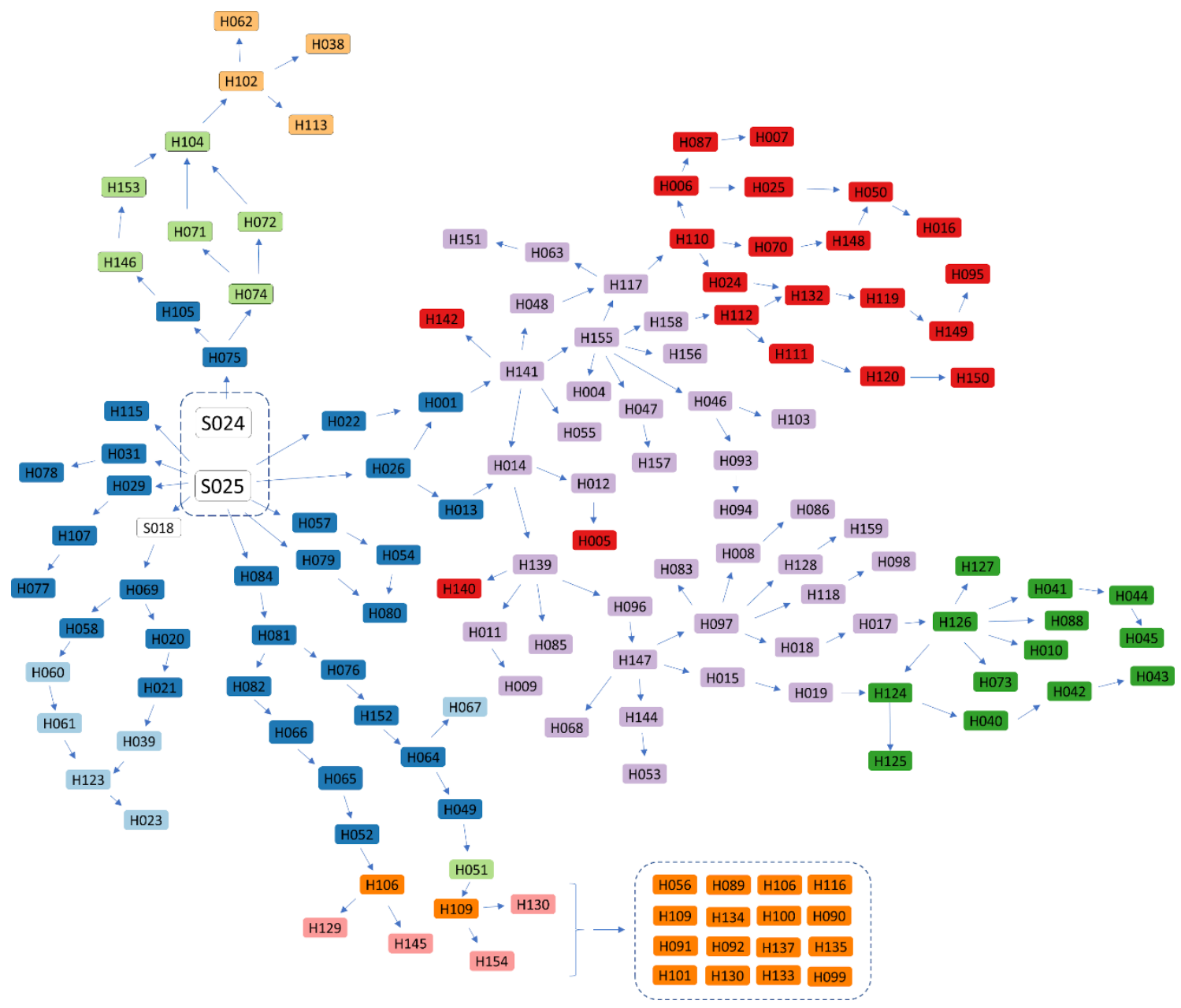

Figure 7. Biosynthetic pathways of the $\mathrm{H}$-steroids colored according to the cluster to which each individual compound belongs.

In addition, Figure 7 clearly shows that the arrangement of the rest of the compounds in defined regions of the biosynthetic pathway map also closely correlates with the cluster they belong to. As a result, some interesting trends can be unveiled: it is known that cleavage of the side chain present in cholesterol, catalyzed by the enzyme CYP11A, is only found in vertebrates, and that these steroidogenic pathways producing glucocorticoids and reproductive steroids (included in clusters \#1,\#3 and \#9) are several hundred million years old. ${ }^{36}$ Our analysis shows that this unique biosynthetic step introduces such important structural changes on the properties so as to 
establish a well-defined frontier between cluster \#2 and the aforementioned clusters. In a similar way, aromatization of the six-membered A ring of androgens (included in cluster \#9) by the enzyme CYP19A1 leads to a set of compounds (estrogens in cluster \#1) that lie far from the rest of $\mathrm{H}$-steroids in the chemical space.

In recent work on the evolution of steroidogenic enzymes and the timing of their appearance, Markov et al. suggest that the first pathway to appear led to the synthesis of oxysterols, followed by dafachronic acids, ecdysones, and progestagens, and that most of vertebrate bile acids, sex and adrenal steroids surfaced during a later phase of diversification ${ }^{21}$. Our findings also indicate that such diversification of enzymatic pathways paralleled the broadening of the properties of steroids they produce, allowing the emergence of more complex life forms able to more efficiently regulate their life cycles, but also to better fit to the environment.

As stated before, modern statistical bioinformatic approaches targeted to the comparative analysis of genomes are being used to detect signatures of natural selection at the gene and population level, as an attempt to understand the origin of primordial metabolism and its expansion to form the metabolic networks existing nowadays, with impressive results. Nonetheless, these studies are mainly centered on genes and the proteins they encode, somehow neglecting the small organic chemicals that are, after all, central players in life processes. On the other hand, chemoinformatic techniques are nowadays at the roots of drug design and medicinal chemistry, areas in which assessing the complexity and diversity of compounds is paramount but are seldomly used to address basic biological questions. Only in recent times these techniques have been applied to the study of natural products. ${ }^{31,37-39}$ 
In this work, we have applied chemoinformatic tools to analyze, as a proof of concept, a set of natural steroids and found that even from simple physicochemical and topological properties derived from their molecular graphs, several traits that evolution has imprinted at the metabolite level can be unveiled, suggesting that natural selection also acts on molecular properties as advanced by Firn and Jones.

In this sense, our results clearly show that sterols, the primal steroids that first appeared, have more conserved properties and that, from then on, more complex compounds with increasingly diverse properties have emerged, which is in line with some models that were developed for explaining the evolution of metabolism. It is foreseeable that as more biogenic small organic compounds are discovered and their biosynthetic origins are disclosed, these chemoinformatic approaches could complement the usual genome-based studies, thus contributing to a better understanding of the complex chemical framework of life.

\section{EXPERIMENTAL DETAILS}

\section{Database curation}

Structures of $\mathrm{S}$ - and $\mathrm{H}$ - steroids were extracted from the KEGG PATHWAY database ${ }^{41}$ and PubChem ${ }^{42}$. Structures of M-steroids were collected from the Dictionary of Steroids ${ }^{43}$ and from reports published in the Journal of Natural Products between years 2000 and 2019.

\section{Calculation of the molecular descriptors and statistical analysis}

Calculation of the 64 physicochemical descriptors for S-, $\mathrm{H}$ - and $\mathrm{M}$ - steroids was performed with ChemAxon's JChem for Excel (release 20.11.0.644, 2020, ChemAxon; http://www.chemaxon.com). Statistical analysis, unsupervised machine learning techniques 
(dimensionality reduction and clustering) and data visualization were carried out with $\mathrm{R}$ version 3.6.1 using the packages factoextra, factoMineR, dendextend and ggplot2.

\section{ASSOCIATED CONTENT}

\section{Supplementary information}

List of the sixty-four properties and molecular descriptors used in this work. Table containing the names and codes of the natural steroids collected in the database. Additional statistical results.

\section{ACKNOWLEDGMENTS}

This work was supported by grants from Universidad de Buenos Aires (UBACyT 20020170100679BA and 20020170100247BA). We are grateful to Ms. Maria Marta Rancez for her assistance with English language editing and to Miss Ana Ramírez for helping with the preparation of the figures.

\section{REFERENCES}

(1) Kroymann, J. Natural Diversity and Adaptation in Plant Secondary Metabolism. Curr. Opin. Plant Biol. 2011, 14 (3), 246-251. https://doi.org/10.1016/j.pbi.2011.03.021.

(2) Fani, R.; Fondi, M. Origin and Evolution of Metabolic Pathways. Phys. Life Rev. 2009, 6 (1), 23-52. https://doi.org/10.1016/j.plrev.2008.12.003.

(3) Scossa, F.; Fernie, A. R. The Evolution of Metabolism: How to Test Evolutionary Hypotheses at the Genomic Level. Comput. Struct. Biotechnol. J. 2020, 18, 482-500. 
https://doi.org/10.1016/j.csbj.2020.02.009.

(4) Firn, R. D.; Jones, C. G. The Evolution of Secondary Metabolism - A Unifying Model. Mol. Microbiol. 2000, 37 (5), 989-994. https://doi.org/10.1046/j.1365-2958.2000.02098.x.

(5) Firn, R. D.; Jones, C. G. A Darwinian View of Metabolism: Molecular Properties Determine Fitness. J. Exp. Bot. 2009, 60 (3), 719-726. https://doi.org/10.1093/jxb/erp002.

(6) Lednicer, D. Steroid Chemistry at a Glance; Chemistry At a Glance; Wiley, 2011.

(7) Brown, A. J.; Galea, A. M. Cholesterol as an Evolutionary Response to Living with Oxygen. Evolution (N. Y). 2010, 64 (7), 2179-2183. https://doi.org/10.1111/j.15585646.2010.01011.x.

(8) Galea, A. M.; Brown, A. J. Special Relationship between Sterols and Oxygen: Were Sterols an Adaptation to Aerobic Life? Free Radic. Biol. Med. 2009, 47 (6), 880-889. https://doi.org/10.1016/j.freeradbiomed.2009.06.027.

(9) Gold, D. A.; Caron, A.; Fournier, G. P.; Summons, R. E. Paleoproterozoic Sterol Biosynthesis and the Rise of Oxygen. Nature 2017, 543 (7645), 420-423. https://doi.org/10.1038/nature21412.

(10) Widomska, J.; Raguz, M.; Subczynski, W. K. Oxygen Permeability of the Lipid Bilayer Membrane Made of Calf Lens Lipids. Biochim. Biophys. Acta-Biomembr. 2007, 1768 (10), 2635-2645. https://doi.org/10.1016/j.bbamem.2007.06.018.

(11) Dotson, R. J.; Smith, C. R.; Bueche, K.; Angles, G.; Pias, S. C. Influence of Cholesterol on the Oxygen Permeability of Membranes: Insight from Atomistic Simulations. Biophys. J. 2017, 112 (11), 2336-2347. https://doi.org/10.1016/j.bpj.2017.04.046. 
(12) Khan, N.; Shen, J.; Chang, T. Y.; Chang, C. C.; Fung, P. C. W.; Grinberg, O.; Demidenko, E.; Swartz, H. Plasma Membrane Cholesterol: A Possible Barrier to Intracellular Oxygen in Normal and Mutant CHO Cells Defective in Cholesterol Metabolism. Biochemistry 2003, 42 (1), 23-29. https://doi.org/10.1021/bi026039t.

(13) Popova, A. V; Velitchkova, M.; Zanev, Y. Effect of Membrane Fluidity on Photosynthetic Oxygen Production Reactions. Z. Naturforsch. C. 62 (3-4), 253-260.

(14) Schaller, H. The Role of Sterols in Plant Growth and Development. Prog. Lipid Res. 2003, 42 (3), 163-175. https://doi.org/10.1016/S0163-7827(02)00047-4.

(15) Tamura, T.; Akihisa, T.; Kokke, W. Naturally Occurring Sterols and Related Compounds from Plants. In Physiology and Biochemistry of Sterols; AOCS Publishing, 1992; pp 172228. https://doi.org/10.1201/9781439821831.ch7.

(16) Bento, G.; Ogawa, A.; Sommer, R. J. Co-Option of the Hormone-Signalling Module Dafachronic Acid-DAF-12 in Nematode Evolution. Nature 2010, 466 (7305), 494-497. https://doi.org/10.1038/nature09164.

(17) Niwa, R.; Niwa, Y. S. Enzymes for Ecdysteroid Biosynthesis: Their Biological Functions in Insects and Beyond. Biosci. Biotechnol. Biochem. 2014, 78 (8), 1283-1292. https://doi.org/10.1080/09168451.2014.942250.

(18) Honda, Y.; Ishiguro, W.; Ogihara, M. H.; Kataoka, H.; Taylor, D. M. Identification and Expression of Nuclear Receptor Genes and Ecdysteroid Titers during Nymphal Development in the Spider Agelena Silvatica. Gen. Comp. Endocrinol. 2017, 247, 183-198. https://doi.org/10.1016/j.ygcen.2017.01.032.

(19) Nakagawa, Y.; Henrich, V. C. Arthropod Nuclear Receptors and Their Role in Molting. FEBS 
J. 2009, 276 (21), 6128-6157. https://doi.org/10.1111/j.1742-4658.2009.07347.x.

(20) Fonseca, E.; Ruivo, R.; Lopes-Marques, M.; Zhang, H.; Santos, M. M.; Venkatesh, B.; Castro, L. F. C. LXR $\alpha$ and LXR $\beta$ Nuclear Receptors Evolved in the Common Ancestor of Gnathostomes. Genome Biol. Evol. 2017, 9 (1), 222-230.

https://doi.org/10.1093/gbe/evw305.

(21) Markov, G. V.; Gutierrez-Mazariegos, J.; Pitrat, D.; Billas, I. M. L.; Bonneton, F.; Moras, D.; Hasserodt, J.; Lecointre, G.; Laudet, V. Origin of an Ancient Hormone/Receptor Couple Revealed by Resurrection of an Ancestral Estrogen. Sci. Adv. 2017, 3 (3), 1-14. https://doi.org/10.1126/sciadv.1601778.

(22) Markov, G. V; Tavares, R.; Dauphin-Villemant, C.; Demeneix, B. A.; Baker, M. E.; Laudet, V. Independent Elaboration of Steroid Hormone Signaling Pathways in Metazoans. Proc NatI Acad Sci U S A 2009, 106 (29), 11913-11918. https://doi.org/10.1073/pnas.0812138106.

(23) Thummel, C. S.; Chory, J. Steroid Signaling in Plants and Insects - Common Themes, Different Pathways. Genes Dev. 2002, 16 (24), 3113-3129. https://doi.org/10.1101/gad.1042102.

(24) Jiang, Y. Y.; Kong, D. X.; Qin, T.; Zhang, H. Y. How Does Oxygen Rise Drive Evolution? Clues from Oxygen-Dependent Biosynthesis of Nuclear Receptor Ligands. Biochem. Biophys. Res. Commun. 2010, 391 (2), 1158-1160. https://doi.org/10.1016/j.bbrc.2009.11.041.

(25) Tianero, M. D.; Pierce, E.; Raghuraman, S.; Sardar, D.; McIntosh, J. A.; Heemstra, J. R.; Schonrock, Z.; Covington, B. C.; Maschek, J. A.; Cox, J. E.; et al. Metabolic Model for Diversity-Generating Biosynthesis. Proc. Natl. Acad. Sci. 2016, 113 (7), 1772-1777. https://doi.org/10.1073/pnas.1525438113. 
(26) Zhang, Y.; Deng, T.; Sun, L.; Landis, J. B.; Moore, M. J.; Wang, H.; Wang, Y.; Hao, X.; Chen, J.; Li, S.; et al. Phylogenetic Patterns Suggest Frequent Multiple Origins of Secondary Metabolites across the Seed Plant "Tree of Life." Natl. Sci. Rev. 2020. https://doi.org/10.1093/nsr/nwaa105.

(27) Härdle, W. K.; Simar, L. Applied Multivariate Statistical Analysis; Springer Berlin Heidelberg: Berlin, Heidelberg, 2015. https://doi.org/10.1007/978-3-662-45171-7.

(28) Granick, S. Speculations On The Origins And Evolution Of Photosynthesis. Ann. N. Y. Acad. Sci. 1957, 69 (2), 292-308. https://doi.org/10.1111/j.1749-6632.1957.tb49665.x.

(29) Souza, C. M.; Schwabe, T. M. E.; Pichler, H.; Ploier, B.; Leitner, E.; Guan, X. L.; Wenk, M. R.; Riezman, I.; Riezman, H. A Stable Yeast Strain Efficiently Producing Cholesterol Instead of Ergosterol Is Functional for Tryptophan Uptake, but Not Weak Organic Acid Resistance. Metab. Eng. 2011, 13 (5), 555-569. https://doi.org/10.1016/j.ymben.2011.06.006.

(30) Baker, M. E. Xenobiotics and the Evolution of Multicellular Animals: Emergence and Diversification of Ligand-Activated Transcription Factors. Integr. Comp. Biol. 2005, 45 (1), 172-178. https://doi.org/10.1093/icb/45.1.172.

(31) Shang, J.; Hu, B.; Wang, J.; Zhu, F.; Kang, Y.; Li, D.; Sun, H.; Kong, D. X.; Hou, T. Cheminformatic Insight into the Differences between Terrestrial and Marine Originated Natural Products. J. Chem. Inf. Model. 2018, 58 (6), 1182-1193. https://doi.org/10.1021/acs.jcim.8b00125.

(32) Chen, J. K.; Taipale, J.; Cooper, M. K.; Beachy, P. A. Inhibition of Hedgehog Signaling by Direct Binding of Cyclopamine to Smoothened. Genes Dev. 2002, 16 (21), 2743-2748. https://doi.org/10.1101/gad.1025302. 
(33) Li, H. L.; Hadid, D.; Ragsdale, D. S. The Batrachotoxin Receptor on the Voltage-Gated Sodium Channel Is Guarded by the Channel Activation Gate. Mol. Pharmacol. 2002, 61 (4), 905-912. https://doi.org/10.1124/mol.61.4.905.

(34) Firn, R. D.; Jones, C. G. Natural Products - A Simple Model to Explain Chemical Diversity. Nat. Prod. Rep. 2003, 20 (4), 382-391. https://doi.org/10.1039/b208815k.

(35) Kubat, M. Unsupervised Learning. In An Introduction to Machine Learning; Springer International Publishing: Cham, 2017; pp 273-295. https://doi.org/10.1007/978-3-31963913-0_14.

(36) Goldstone, J. V.; Sundaramoorthy, M.; Zhao, B.; Waterman, M. R.; Stegeman, J. J.; Lamb, D. C. Genetic and Structural Analyses of Cytochrome P450 Hydroxylases in Sex Hormone Biosynthesis: Sequential Origin and Subsequent Coevolution. Mol. Phylogenet. Evol. 2016, 94, 676-687. https://doi.org/10.1016/j.ympev.2015.09.012.

(37) Ertl, P.; Schuhmann, T. A Systematic Cheminformatics Analysis of Functional Groups Occurring in Natural Products. J. Nat. Prod. 2019, 82 (5), 1258-1263. https://doi.org/10.1021/acs.jnatprod.8b01022.

(38) González-Medina, M.; Medina-Franco, J. L. Chemical Diversity of Cyanobacterial Compounds: A Chemoinformatics Analysis. ACS Omega 2019, 4 (4), 6229-6237. https://doi.org/10.1021/acsomega.9b00532.

(39) Saldívar-González, F. I.; Valli, M.; Andricopulo, A. D.; Da Silva Bolzani, V.; Medina-Franco, J. L. Chemical Space and Diversity of the NuBBE Database: A Chemoinformatic Characterization. J. Chem. Inf. Model. 2019, 59 (1), 74-85. https://doi.org/10.1021/acs.jcim.8b00619. 
(40) Kawaide, H. Biochemical and Molecular Analyses of Gibberellin Biosynthesis in Fungi.

Biosci. Biotechnol. Biochem. 2006, 70 (3), 583-590. https://doi.org/10.1271/bbb.70.583.

(41) Kanehisa, M. KEGG: Kyoto Encyclopedia of Genes and Genomes. Nucleic Acids Res. 2000, 28 (1), 27-30. https://doi.org/10.1093/nar/28.1.27.

(42) Kim, S.; Chen, J.; Cheng, T.; Gindulyte, A.; He, J.; He, S.; Li, Q.; Shoemaker, B. A.; Thiessen, P. A.; Yu, B.; et al. PubChem 2019 Update: Improved Access to Chemical Data. Nucleic Acids Res. 2019, 47 (D1), D1102-D1109. https://doi.org/10.1093/nar/gky1033.

(43) Hill, R. A.; Makin, H. L. J.; Kirk, D. N.; Murphy, G. M. Dictionary of Steroids; Taylor \& Francis, 1991. 


\section{SUPPLEMENTARY INFORMATION}

Tracing Molecular Properties Throughout Evolution: A Chemoinformatic Approach.

Marcelo Otero ${ }^{a, b}$, Silvina N. Sarno ${ }^{c}$, Sofía L. Acebedo ${ }^{\text {,e }}$, Javier A. Ramírez ${ }^{\text {,e* }}$.

${ }^{+}$Universidad de Buenos Aires. Facultad de Ciencias Exactas y Naturales. Departamento de Física. Buenos Aires, Argentina.

${ }^{\ddagger}$ CONICET - Universidad de Buenos Aires. Instituto de Física de Buenos Aires (IFIBA). Buenos Aires, Argentina.

${ }^{\S}$ Escuela de Ciencia y Tecnología, Universidad Nacional de San Martín, Martín de Irigoyen 3100, 1650, San Martín, Provincia de Buenos Aires, Argentina.

${ }^{\perp}$ Universidad de Buenos Aires. Facultad de Ciencias Exactas y Naturales. Departamento de Química Orgánica. Buenos Aires, Argentina.

"CONICET - Universidad de Buenos Aires. Unidad de Microanálisis y Métodos Físicos Aplicados a Química Orgánica (UMYMFOR). Buenos Aires, Argentina.

* Corresponding author. E-mail: jar@qo.fcen.uba.ar. Tel: +541145763385

Table of Contents.

List of molecular descriptors used in the analysis $\quad$ S2

Database of natural steroids $\quad$ S3

Comparative box-and-whisker plots for the calculated descriptors $\quad$ S15

$\begin{array}{ll}\text { Additional results from the PCA analysis } & \text { S19 }\end{array}$ 


\section{Molecular properties and descriptors used in this work.}

Sixty-four molecular descriptors and molecular properties were calculated for every compound. The molecular properties and descriptors were calculated with Chemaxon JChem for Excel (release 20.11.0.644, 2020, ChemAxon; http://www.chemaxon.com) and classified in groups according to the descriptor nature:

Elemental Analysis descriptors: Molecular weight (MW), Atom Count (AC), Heavy Atom Count (HAC), C Atom Count (C), O Atom Count (O), N Atom Count (N), F Atom Count (F), Cl Atom Count $(\mathrm{Cl}), \mathrm{Br}$ Atom Count $(\mathrm{Br}), \mathrm{I}$ Atom Count (I), P Atom Count (P) and H Atom Count (H).

Hydrogen Bond Donor-acceptor properties: Hydrogen Bond Acceptor Count (HBA) and Hydrogen Bond Donor Count (HBD).

Partitioning and Distribution Properties: calculated n-Octanol / Water distribution coefficient: Log $\mathrm{D}$ (at pH: 7.4) and calculated n-Octanol / Water partition coefficient Log P.

Global Topological Indices based in 2D-molecular graphs: Path based indices: Platt Index and Randic Index. Distance based indices: Balaban Index, Harary Index, Hyper Wiener Index, Szeged Index and Wiener Index.

Geometric Properties: Maximal and Minimal Projection Area (based in the Van der Waals Radius), Maximal and Minimal Projection Radius, Van der Waals Molecular Volume (VWMV), Van der Waals Surface Area (VWSA), Topological Polar Surface Area (tPSA), Rotatable Bond Count (RotB) and RelPSA defined as tPSA/VWSA. Although Refractivity is an optical property, is highly related to molecular volume. Thus, we included it in this group.

Ring Properties: Ring Atom Count, Ring Bond Count, Aromatic Atom Count, Aromatic Bond Count, Ring Count, the Cyclomatic Number, Aromatic Ring Count, Aliphatic Ring Count, Largest Ring Size, Smallest Ring Size, Carbo Ring Count, Carbo Aromatic Ring Count, Fused Ring Count, Fused Aliphatic Ring Count, Fused Aromatic Ring Count, Hetero Ring Count, Hetero Aromatic Ring Count, Ring System Count, Largest Ring System Size, Smallest Ring System Size and RRSys defined as Ring Count / Ring System Count.

Chain Properties: Aliphatic Atom Count, Aliphatic Bond Count, Bond Count, Chain Atom Count, Chain Bond Count and Fragment Count.

Molecular Complexity Properties: Fraction of sp3 Carbon Atoms (Fsp3), Chiral Center Count (nStereo), Asymmetric Atom Count and nStMW defined as nStereo/MW. 
Table S1. Natural steroids included in the database

\begin{tabular}{|c|c|}
\hline Code & Name \\
\hline H001 & 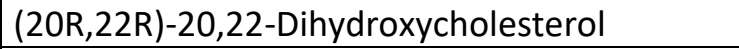 \\
\hline $\mathrm{H} 002$ & (20S)-Cholesta-5-ene-3 $\beta, 17,20$-triol \\
\hline H003 & (25S)-Dafachronic acid \\
\hline $\mathrm{H} 004$ & $11 \alpha$-Hydroxyprogesterone \\
\hline H005 & $11 \beta, 17 \alpha, 21$-Trihydroxypregnenolone \\
\hline H006 & $11 \beta, 18,21$-Trihydroxy-pregn-4-ene-3,20-dione \\
\hline $\mathrm{H} 007$ & $11 \beta, 21$-Dihydroxy-3,20-oxo-5 $\beta$-pregnan-18-al \\
\hline H008 & $11 \beta$-Hydroxyandrostenedione \\
\hline H0O9 & $16 \alpha-$ Hydroxyandrostenedione \\
\hline $\mathrm{H} 010$ & $16 \alpha$-Hydroxyestrone \\
\hline H011 & 16-Hydroxydehydroepiandrosterone \\
\hline $\mathrm{H} 012$ & 17,21-Dihydroxypregnenolone \\
\hline $\mathrm{H} 013$ & $17 \alpha, 20 \alpha$-Dihydroxycholesterol \\
\hline H014 & 17 $\alpha$-Hydroxypregnenolone \\
\hline H015 & $17 \beta, 19-D i h y d r o x y a n d r o s t-4-e n-3-o n e$ \\
\hline H016 & 17-Deoxycortolone \\
\hline H017 & 19-Aldoandrostenedione \\
\hline H018 & 19-Hydroxyandrostenedione \\
\hline H019 & 19-Oxotestosterone \\
\hline $\mathrm{H} 020$ & 2,22,25-Trideoxyecdysone \\
\hline H021 & 2,22-Dideoxyecdysone \\
\hline H022 & $20 \alpha-H y d r o x y c h o l e s t e r o l$ \\
\hline $\mathrm{H} 023$ & 20-Hydroxyecdysone \\
\hline $\mathrm{H} 024$ & 21-Deoxycortisol \\
\hline $\mathrm{H} 025$ & 21-Hydroxy-5 $\beta$-pregnane-3,11,20-trione \\
\hline $\mathrm{H} 026$ & 22R-Hydroxycholesterol \\
\hline $\mathrm{H} 027$ & 24-Epibrassinolide \\
\hline $\mathrm{H} 028$ & 24-Epicastasterone \\
\hline H029 & 24-Hydroxycholesterol \\
\hline $\mathrm{H} 030$ & 25-Deoxyecdysone \\
\hline H031 & 25-Hydroxycholesterol \\
\hline $\mathrm{HO32}$ & 25-Methylcastasterone \\
\hline H033 & 27-Hydroxycholesterol \\
\hline H034 & 28-Homobrassinolide \\
\hline H035 & 28-Homodolicholide \\
\hline H036 & 28-Norbrassinolide \\
\hline $\mathrm{H} 037$ & 28-Norcastasterone \\
\hline H038 & 2-Deoxybrassinolide \\
\hline
\end{tabular}




\begin{tabular}{|c|c|}
\hline H039 & 2-Deoxyecdysone \\
\hline $\mathrm{H} 040$ & 2-Hydroxyestradiol \\
\hline H041 & 2-Hydroxyestrone \\
\hline $\mathrm{H} 042$ & 2-Methoxyestradiol \\
\hline $\mathrm{H} 043$ & 2-Methoxyestradiol-17 $\beta$-3-sulfate \\
\hline $\mathrm{H} 044$ & 2-Methoxyestrone \\
\hline $\mathrm{H} 045$ & 2-Methoxyestrone-3-sulfate \\
\hline $\mathrm{H} 046$ & 3,20-Allopregnanedione \\
\hline $\mathrm{H} 047$ & 3,20-Pregnanedione \\
\hline $\mathrm{H} 048$ & 3,21-Dihydroxypregn-5-en-20-one \\
\hline $\mathrm{H} 049$ & 3,7,12-Trihydroxycholestan-26-al \\
\hline $\mathrm{H} 050$ & 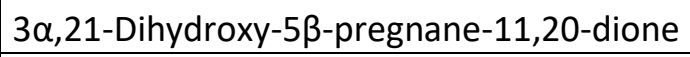 \\
\hline H051 & $3 \alpha, 7 \alpha, 12 \alpha$-Trihydroxy- $5 \beta$-cholestanate \\
\hline $\mathrm{H} 052$ & $3 \alpha, 7 \alpha$-Dihydroxy-5$\beta$-cholestan-26-al \\
\hline H053 & $3 \alpha$-Androstanediol \\
\hline $\mathrm{H} 054$ & $3 \beta, 7 \alpha$-Dihydroxy-5-cholestenoate \\
\hline $\mathrm{H} 055$ & 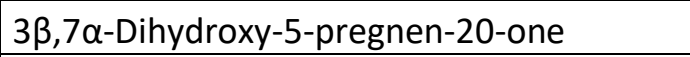 \\
\hline H056 & $3 \beta$-Deoxycholic acid \\
\hline $\mathrm{H} 057$ & $3 \beta$-Hydroxy-5-cholestenoate \\
\hline $\mathrm{H} 058$ & 3-Dehydro-2,22-deoxyecdysone \\
\hline $\mathrm{H} 059$ & 3-Dehydro-20-hydroxyecdysone \\
\hline H060 & 3-Dehydro-2-deoxyecdysone \\
\hline $\mathrm{H} 061$ & 3-Dehydroecdysone \\
\hline H062 & 3-Epibrassinolide \\
\hline $\mathrm{H} 063$ & $5 \alpha$-Dihydrodeoxycorticosterone \\
\hline H064 & $5 \beta$-Cholestane- $3 \alpha, 7 \alpha, 12 \alpha, 26$-tetrol \\
\hline $\mathrm{H} 065$ & $5 \beta$-Cholestane- $3 \alpha, 7 \alpha, 26$-triol \\
\hline H066 & $5 \beta$-Cholestane- $3 \alpha, 7 \alpha$-diol \\
\hline $\mathrm{H} 067$ & $5 \beta$-Cyprinolsulfate \\
\hline H068 & $5 \beta$-Dihydrotestosterone \\
\hline H069 & $5 \beta$-Diketol \\
\hline $\mathrm{H} 070$ & $5 \beta$-Pregnane- $11 \beta, 21$-diol-3,20-dione \\
\hline $\mathrm{H} 071$ & $6 \alpha$-Hydroxycastasterone \\
\hline $\mathrm{H} 072$ & $6 \beta$-Hydroxycastasterone \\
\hline $\mathrm{H} 073$ & $6 \beta$-Hydroxyestradiol-17 $\beta$ \\
\hline $\mathrm{H} 074$ & 6-Deoxocastasterone \\
\hline $\mathrm{H} 075$ & 6-Deoxocathasterone \\
\hline H076 & $7 \alpha, 12 \alpha$-Dihydroxy-5 $\beta$-cholestan-3-one \\
\hline $\mathrm{H} 077$ & 7a,24-Dihydroxycholest-4-en-3-one \\
\hline $\mathrm{H} 078$ & 7a,25-Dihydroxycholesterol \\
\hline H079 & 7a,27-Dihydroxycholesterol \\
\hline
\end{tabular}




\begin{tabular}{|c|c|}
\hline $\mathrm{H} 080$ & 7a-Hydroxy-3-oxo-4-cholestenoate \\
\hline $\mathrm{H} 081$ & 7a-Hydroxy-4-cholesten-3-one \\
\hline $\mathrm{H} 082$ & $7 \alpha$-Hydroxy-5 $\beta$-cholestan-3-one \\
\hline $\mathrm{H} 083$ & 7a-Hydroxyandrost-4-ene-3,17-dione \\
\hline $\mathrm{H} 084$ & 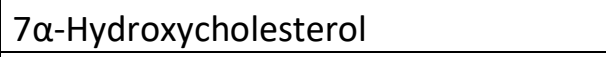 \\
\hline $\mathrm{H} 085$ & $7 \alpha-$ Hydroxydehydroepiandrosterone \\
\hline $\mathrm{H} 086$ & Adrenosterone \\
\hline $\mathrm{H} 087$ & Aldosterone \\
\hline $\mathrm{H} 088$ & Alfatradiol \\
\hline H089 & Alloavicholicacid \\
\hline H090 & Allochenodeoxycholicacid \\
\hline H091 & Allocholicacid \\
\hline H092 & Allodeoxycholicacid \\
\hline $\mathrm{H} 093$ & Allopregnan-20 $\alpha$-ol-3-one \\
\hline H094 & Allopregnane-3 $\alpha, 20 \alpha$-diol \\
\hline $\mathrm{H} 095$ & $\alpha$-Cortol \\
\hline H096 & Androstenediol \\
\hline $\mathrm{H} 097$ & Androstenedione \\
\hline $\mathrm{H} 098$ & Androsterone \\
\hline H099 & Avicholicacid \\
\hline $\mathrm{H} 100$ & Avideoxycholicacid \\
\hline H101 & Bitocholicacid \\
\hline $\mathrm{H} 102$ & Brassinolide \\
\hline $\mathrm{H} 103$ & Brexanolone \\
\hline $\mathrm{H} 104$ & Castasterone \\
\hline H105 & Cathasterone \\
\hline $\mathrm{H} 106$ & Chenodiol \\
\hline $\mathrm{H} 107$ & Cholest-5-en-3 $\beta, 7 \alpha, 24 S$-triol \\
\hline $\mathrm{H} 108$ & Cholesteryl sulfate \\
\hline H109 & Cholicacid \\
\hline $\mathrm{H} 110$ & Corticosterone \\
\hline H111 & Cortisone \\
\hline $\mathrm{H} 112$ & Cortodoxone \\
\hline $\mathrm{H} 113$ & Cryptolide \\
\hline $\mathrm{H} 114$ & $\Delta(7)$-Dafachronicacid \\
\hline $\mathrm{H} 115$ & $\Delta(4)$-Dafachronic acid \\
\hline $\mathrm{H} 116$ & Deoxycholic acid \\
\hline $\mathrm{H} 117$ & Desoxycortone \\
\hline $\mathrm{H} 118$ & Dihydroandrostenedione \\
\hline $\mathrm{H} 119$ & Dihydrocortisol \\
\hline $\mathrm{H} 120$ & 4,5 $\beta$-Dihydrocortisone \\
\hline
\end{tabular}




\begin{tabular}{|c|c|}
\hline $\mathrm{H} 121$ & Dolicholide \\
\hline $\mathrm{H} 122$ & Dolichosterone \\
\hline $\mathrm{H} 123$ & Ecdysone \\
\hline $\mathrm{H} 124$ & Estradiol \\
\hline $\mathrm{H} 125$ & Estradiol 3-sulfate \\
\hline $\mathrm{H} 126$ & Estrone \\
\hline $\mathrm{H} 127$ & Estrone sulfate \\
\hline $\mathrm{H} 128$ & Etiocholanedione \\
\hline H129 & Glycochenodeoxycholic acid \\
\hline $\mathrm{H} 130$ & Glycocholicacid \\
\hline $\mathrm{H} 131$ & Homocastasterone \\
\hline $\mathrm{H} 132$ & Hydrocortisone \\
\hline $\mathrm{H} 133$ & Hyodeoxycholicacid \\
\hline $\mathrm{H} 134$ & Isochenodeoxycholic acid \\
\hline H135 & Isolithocholic acid \\
\hline $\mathrm{H} 136$ & Isoursodeoxycholic acid \\
\hline $\mathrm{H} 137$ & Lagodeoxycholic \\
\hline H138 & Ponasterone A \\
\hline H139 & Prasterone \\
\hline $\mathrm{H} 140$ & Prasterone sulfate \\
\hline $\mathrm{H} 141$ & Pregnenolone \\
\hline $\mathrm{H} 142$ & Pregnenolone sulfate \\
\hline $\mathrm{H} 143$ & Secasterol \\
\hline $\mathrm{H} 144$ & Stanolone \\
\hline $\mathrm{H} 145$ & Taurochenodeoxycholic acid \\
\hline $\mathrm{H} 146$ & Teasterone \\
\hline $\mathrm{H} 147$ & Testosterone \\
\hline $\mathrm{H} 148$ & Tetrahydrocorticosterone \\
\hline $\mathrm{H} 149$ & Tetrahydrocortisol \\
\hline $\mathrm{H} 150$ & Tetrahydrocortisone \\
\hline H151 & Tetrahydrodeoxycorticosterone \\
\hline H152 & Trihydroxycholestane \\
\hline $\mathrm{H} 153$ & Typhasterol \\
\hline $\mathrm{H} 154$ & Taurocholicacid \\
\hline $\mathrm{H} 155$ & Progesterone \\
\hline H156 & $11 \beta$-Hydroxyprogesterone \\
\hline $\mathrm{H} 157$ & Pregnanediol \\
\hline $\mathrm{H} 158$ & 17a-Hydroxyprogesterone \\
\hline $\mathrm{H} 159$ & Etiocholan-3 $\alpha$-ol-17-one \\
\hline M001 & (24S)-Isocalysterol \\
\hline M002 & $12 \alpha-H y d r o x y r e s i b u f o g e n i n$ \\
\hline
\end{tabular}




\begin{tabular}{|c|c|}
\hline M003 & 16-Hydroxymacowanitriene \\
\hline M004 & 23-Keto-cladiellin-A \\
\hline M005 & 23-Oeoxyantheridiol \\
\hline M006 & 26-Hydroxycholest-5-en-7-one \\
\hline M007 & 29-Norsengosterone \\
\hline M008 & 3,7-Dihydroxyandrost-5-en-17-one \\
\hline M009 & 31-Hydroxybuxatrienone \\
\hline M010 & 3-Epi-Periplogenin \\
\hline M011 & 3-N-Benzoylcycloprotobuxine D \\
\hline M012 & $5 \beta$-Cholanic acid \\
\hline M013 & 7- $\alpha-\mathrm{OH}-\mathrm{Khasianine}$ \\
\hline M014 & $7 \beta$-Hydroxybufalin \\
\hline M015 & 7-Nor-Ergosterolide \\
\hline M016 & 7-Oxopetrosterol \\
\hline M017 & 7-Oxostigmasterol \\
\hline M018 & 9(11)-Dehydroagapanthagenin \\
\hline M019 & Abieslactone \\
\hline M020 & Abiesolidic acid \\
\hline M021 & Abiesonic acid \\
\hline M022 & Abietospiran \\
\hline M023 & Abrusogenin \\
\hline M024 & Abutasterone \\
\hline M025 & Acanthasterol \\
\hline M026 & Acanthovagasteroid D \\
\hline M027 & Acerionol \\
\hline M028 & Acnistina A \\
\hline M029 & Agapanthagenin \\
\hline M030 & Aglaiol \\
\hline M031 & Aglaiondiol \\
\hline M032 & Agosterol A \\
\hline M033 & Ailanthol \\
\hline M034 & Ajugalactone \\
\hline M035 & Ajugasterone B \\
\hline M036 & Ajugasterone C \\
\hline M037 & Alisol A \\
\hline M038 & Alliogenin \\
\hline M039 & Alnincanone \\
\hline M040 & Alnuserrudiolone \\
\hline M041 & Alnuserrutriol \\
\hline M042 & $\alpha$-Elemolicacid \\
\hline M043 & Amaranzol A \\
\hline
\end{tabular}




\begin{tabular}{|c|c|}
\hline M044 & Amaranzol E \\
\hline M045 & Amoorastatin \\
\hline M046 & Amoorastatone \\
\hline M047 & Amphisterol \\
\hline M048 & Anandin A \\
\hline M049 & Anandin B \\
\hline M050 & Andirobin \\
\hline M051 & Antheridiol \\
\hline M052 & Antiarigenin \\
\hline M053 & Aphanamixin \\
\hline M054 & Aphanastatin \\
\hline M055 & Aphelaketotriol \\
\hline M056 & Aplykurodinone-1 \\
\hline M057 & Aplysterol \\
\hline M058 & Aragusterol A \\
\hline M059 & Arapaimol B \\
\hline M060 & Astrogorgioside C \\
\hline M061 & Barbourgenin \\
\hline M062 & Bethogenin \\
\hline M063 & Butyrospermol \\
\hline M064 & Buxaltine \\
\hline M065 & Buxamine $\mathrm{E}$ \\
\hline M066 & Buxaminol B \\
\hline M067 & Buxozine C \\
\hline M068 & Buxtamine \\
\hline M069 & Cabraleadiol \\
\hline M070 & Cabraleahydroxylactone \\
\hline M071 & Cabralealactone \\
\hline M072 & Cabraleone \\
\hline M073 & Calactin \\
\hline M074 & Calibagenin \\
\hline M075 & Calotoxin \\
\hline M076 & Calotropagenin \\
\hline M077 & Calotropin \\
\hline M078 & Calysterol \\
\hline M079 & Cedrelone \\
\hline M080 & Cephalosporin P1 \\
\hline M081 & Cephalostatin 1 \\
\hline M082 & Cephalostatin 19 \\
\hline M083 & Cerberin \\
\hline M084 & Cerbertin \\
\hline
\end{tabular}




\begin{tabular}{|c|c|}
\hline M085 & Cerevisterol \\
\hline M086 & Cheilanthone B \\
\hline M087 & Chiogralactone \\
\hline M088 & Chiograsterol B \\
\hline M089 & Chiograsterone \\
\hline M090 & Chisocheton F \\
\hline M091 & Chlorogenin \\
\hline M092 & Cholest-4-en-3-one \\
\hline M093 & Cholestane-3,6-dione \\
\hline M094 & Chondrillasterol \\
\hline M095 & Chonemorphine \\
\hline M096 & Cimicifugenol \\
\hline M097 & Cimigenol \\
\hline M098 & Cimigol \\
\hline M099 & Cinanthrenol A \\
\hline M100 & Clerosterol \\
\hline M101 & Clionastatin A \\
\hline M102 & Conicasterol C \\
\hline M103 & Conicasterol E \\
\hline M104 & Coroglaucigenin \\
\hline M105 & Corotoxigenin \\
\hline M106 & Cortistatin J \\
\hline M107 & Cortistatin L \\
\hline M108 & Cortistattin A \\
\hline M109 & Crellastatin A \\
\hline M110 & Crellasterone A \\
\hline M111 & Crinosterol \\
\hline M112 & Cucurbitacin B \\
\hline M113 & Cucurbitacin F \\
\hline M114 & Cyasterone \\
\hline M115 & Cyclobuxamine $\mathrm{H}$ \\
\hline M116 & Cyclobuxine B \\
\hline M117 & Cyclobuxine D \\
\hline M118 & Cyclograndisolide \\
\hline M119 & Cyclolaudenol \\
\hline M120 & Cyclomicrobuxine \\
\hline M121 & Cycloprotobuxine A \\
\hline M122 & Cycloprotobuxine C \\
\hline M123 & Cyclovirobuxine D \\
\hline M124 & Dahurinol \\
\hline M125 & Dehydrooogoniol \\
\hline
\end{tabular}




\begin{tabular}{|c|c|}
\hline M126 & Digitogenin \\
\hline M127 & Diosgenin \\
\hline M128 & Dissectolide \\
\hline M129 & Dragmacidolide A \\
\hline M130 & Dysideasterol $\mathrm{F}$ \\
\hline M131 & Echrebsteroid A \\
\hline M132 & Eichlerialactone \\
\hline M133 & Eichlerianicacid \\
\hline M134 & Ergostanol \\
\hline M135 & Ergosterimide \\
\hline M136 & Ergosterol peroxide \\
\hline M137 & Evodol \\
\hline M138 & Firmanoic acid \\
\hline M139 & Fortisterol \\
\hline M140 & Fukujusonorone \\
\hline M141 & $\nu$-Ergostenol \\
\hline M142 & Gibberoketosterol B \\
\hline M143 & Haliclotriol A \\
\hline M144 & Halistanol J \\
\hline M145 & Haplosamate A \\
\hline M146 & Hebesterol \\
\hline M147 & Hecogenin \\
\hline M148 & Helvolinic acid \\
\hline M149 & Holaromine \\
\hline M150 & Ikshusterol \\
\hline M151 & Imperialine \\
\hline M152 & Incisterol \\
\hline M153 & Inokosterone \\
\hline M154 & Isihippurol A \\
\hline M155 & Isocabralin \\
\hline M156 & Isocycloartenol \\
\hline M157 & Isodaurinol \\
\hline M158 & Isolineolone \\
\hline M159 & Jaborosalactone D \\
\hline M160 & Jervine \\
\hline M161 & Kammogenin \\
\hline M162 & Karatavigenin B \\
\hline M163 & Krempene A \\
\hline M164 & Kryptogenin \\
\hline M165 & Lineolone \\
\hline M166 & Macowamine \\
\hline
\end{tabular}




\begin{tabular}{|c|c|}
\hline M167 & Macowanioxazine \\
\hline M168 & Macowanitriene \\
\hline M169 & Malaitasterol A \\
\hline M170 & Mariesiicacid A \\
\hline M171 & Markogenin \\
\hline M172 & Megacarpidine \\
\hline M173 & Methylangolensate \\
\hline M174 & Mexicanolide \\
\hline M175 & Mexogenin \\
\hline M176 & Miroestrol \\
\hline M177 & Molliorin A \\
\hline M178 & Molliorin B \\
\hline M179 & Monanchosterol A \\
\hline M180 & Nakiterpiosinone $\mathrm{C}$ \\
\hline M181 & N-Benzoylbuxodienine E \\
\hline M182 & N-Benzoyl-O-acetylbuxodienine $\mathrm{E}$ \\
\hline M183 & Neoagigenin \\
\hline M184 & Neogitogenin \\
\hline M185 & Neohecogenin \\
\hline M186 & Neomanogenin \\
\hline M187 & Neomexogenin \\
\hline M188 & Neridienone A \\
\hline M189 & Nicasterol \\
\hline M190 & Odoratin \\
\hline M191 & Oogoniol 1 \\
\hline M192 & Oogoniol 2 \\
\hline M193 & Oogoniol 3 \\
\hline M194 & Penicisteroid A \\
\hline M195 & Pennogenin \\
\hline M196 & Periplogenin \\
\hline M197 & Phallusiasterol A \\
\hline M198 & Phomarol \\
\hline M199 & Phorbasterone C \\
\hline M200 & Phorbasterone D \\
\hline M201 & Photogedunin \\
\hline M202 & Plakinamine $\mathrm{M}$ \\
\hline M203 & Plakinamine $\mathrm{O}$ \\
\hline M204 & Polymastiamide A \\
\hline M205 & Poriferasterol \\
\hline M206 & Pulchrasterol \\
\hline M207 & Rockogenin \\
\hline
\end{tabular}




\begin{tabular}{|c|c|}
\hline M208 & Roxburghiadiol B \\
\hline M209 & Rubrosterone \\
\hline M210 & Rutaevin \\
\hline M211 & Samandaridine \\
\hline M212 & sarchookloide A \\
\hline M213 & sarchookloide B \\
\hline M214 & Sarcostin \\
\hline M215 & Sarmentogenin \\
\hline M216 & Scleronine \\
\hline M217 & shishicrellastatin A \\
\hline M218 & Solanidine \\
\hline M219 & Solasodine \\
\hline M220 & solomonsterol B \\
\hline M221 & Spartopregnenolone \\
\hline M222 & Stigmastanol \\
\hline M223 & Stigmastentriol \\
\hline M224 & Stoloniferone F \\
\hline M225 & Stoloniferone $\mathrm{H}$ \\
\hline M226 & Strophadogenin \\
\hline M227 & Swinhoeisterol A \\
\hline M228 & Swinhosterol B \\
\hline M229 & Syriogenin \\
\hline M230 & Theonellasterone \\
\hline M231 & Thornasterol A \\
\hline M232 & triumfettoside \\
\hline M233 & Triumfettosterol \\
\hline M234 & Turkesterone \\
\hline M235 & Uscharidin \\
\hline M236 & Uscharin \\
\hline M237 & Uzarigenin \\
\hline M238 & Voruscharin \\
\hline M239 & Withacnistin \\
\hline $\mathrm{M} 240$ & Xuxuarin B \\
\hline M241 & Yonarasterol I \\
\hline M242 & Yuccagenin \\
\hline M243 & 19-Norcholestane-1,3,5(10),22-tetraene-3-ol \\
\hline M244 & (22E)-24,26-cyclo-19-norcholesta-1,3,5(10),22-tetraen-3-ol \\
\hline M245 & $(3 \beta, 24 R, 25 S)-28-M e t h y l-24,26$-cyclostigmast-5-en-3-ol \\
\hline M246 & 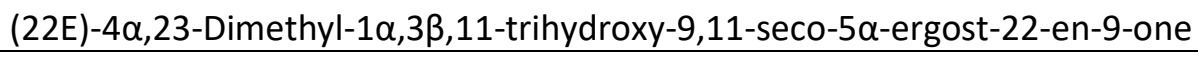 \\
\hline M247 & PubChem CID139051522 \\
\hline M248 & Petasitosterone C \\
\hline
\end{tabular}




\begin{tabular}{|c|c|}
\hline M249 & 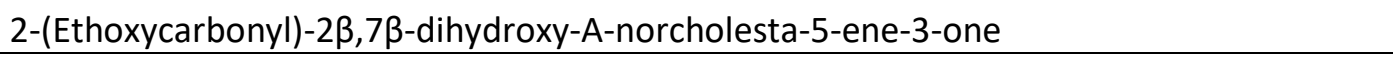 \\
\hline M250 & (22E,24S)-24-Methylcholesta-4,22-diene-3 $\beta, 6 \beta$-diol \\
\hline M251 & Nebrosteroid O \\
\hline M252 & $(3 \beta, 12 \beta, 16 \beta, 23 E)$-cholesta-5,23-diene-3,12,16,20,25-pentaol \\
\hline M253 & 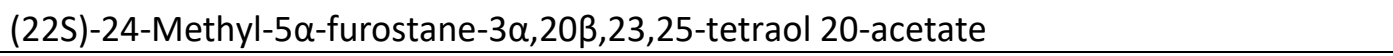 \\
\hline M254 & PubChem CID54769263 \\
\hline M255 & 3-Oxochola-1,4-dien-24-oic acid \\
\hline M256 & $5 \alpha$-cholestan-3 $\alpha, 12 \alpha, 16 \alpha$-triol \\
\hline M257 & Ptilosteroid C \\
\hline M258 & Ptilosteroid A \\
\hline M259 & 2a-Hydroxy-4,7-dioxo-2,4-cyclo-3,4-secocholesta-5-ene-3-oic acid ethyl ester \\
\hline M260 & (24S)-2 $\alpha$-Hydroxy-4,7-dioxo-2,4-cyclo-3,4-secostigmasta-5-ene-3-oic acid ethyl ester \\
\hline M261 & (24R)-3ß-Hydroxy-24-methyl-26,27-dinorcholesta-5-Ene-25-oic Acid \\
\hline M262 & 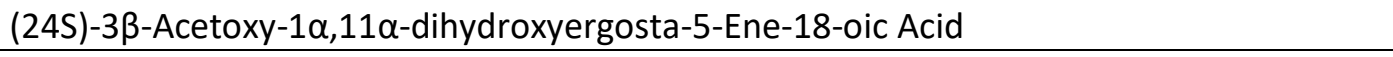 \\
\hline M263 & 3-Oxochola-1,4,22-triene-24-oic acid \\
\hline M264 & PubChem CID11441813 \\
\hline M265 & 18,22-Epoxycholesta-5,20(22)-diene-3ß-ol \\
\hline M266 & 22,23-Epoxycholesta-5-ene-3 $\beta, 17 \alpha$-diol \\
\hline M267 & PubChem CID21725282 \\
\hline M268 & Clathriol \\
\hline M269 & 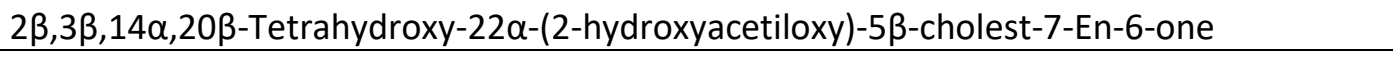 \\
\hline $\mathrm{M} 270$ & $(20 R, 22 R)-2 \beta, 3 \beta, 14 \alpha, 20 \beta, 25$-pentahydroxy-22 $\alpha$-(hydroxyacetoxy)-5 $\beta$-cholest-7-en-6-one \\
\hline M271 & 20S-Hydroxycholest-1-en-3,16-dione \\
\hline M272 & PubChem CID10577697 \\
\hline M273 & PubChem CID14541042 \\
\hline M274 & PubChem CID21634647 \\
\hline M275 & Verarine \\
\hline M276 & PubChem CID134146452 \\
\hline M277 & (20 S)-(benzamido)-3 $\beta$-(N,N-dimethyamino)-pregnane \\
\hline M278 & $1 \beta, 3 \beta$-dihydroxy $22 \alpha \mathrm{N}$-spirosol-5-ene \\
\hline M279 & Tomatidine \\
\hline M280 & Tanghinigenin \\
\hline M281 & Digitoxigenin \\
\hline S001 & 14-Demethyllanosterol \\
\hline S002 & 24-Epi-campesterol \\
\hline S003 & 24-Ethylidenelophenol \\
\hline S004 & 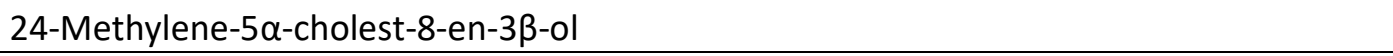 \\
\hline S005 & 24-Methylenecholesterol \\
\hline S006 & 24-Methylenecycloartanol \\
\hline S007 & 3-Keto-4-methylzymosterol \\
\hline S008 & 4,4-Dimethyl-8,24-cholestadienol \\
\hline
\end{tabular}




\begin{tabular}{|c|c|}
\hline S009 & 4,4-dimethylcholest-8(9)-en-3ß-ol \\
\hline S010 & 4,4-Dimethylcholesta-8,14,24-trienol \\
\hline S011 & $4 \alpha$-Carboxy-4b-methyl-5a-cholesta-8,24-dien-3b-ol \\
\hline S012 & $4 \alpha$-Methylfecosterol \\
\hline S013 & $4 \alpha$-Methylzymosterol \\
\hline S014 & 4a-Methylzymosterol-4-carboxylate \\
\hline S015 & 5,7,24(28)-Ergostatrienol \\
\hline S016 & 5-Dehydroavenasterol \\
\hline S017 & 5-Dehydroepisterol \\
\hline S018 & 7-Dehydrocholesterol \\
\hline S019 & 7-Dehydrodesmosterol \\
\hline SO20 & 9६-Episterol \\
\hline S021 & Avenasterol \\
\hline S022 & $\beta$-Sitosterol \\
\hline S023 & Brassicasterol \\
\hline S024 & Campesterol \\
\hline S025 & Cholesterol \\
\hline S026 & Cycloartenol \\
\hline S027 & Cycloeucalenol \\
\hline S028 & $\delta 8,14$-Sterol \\
\hline S029 & Desmosterol \\
\hline S030 & Dihydrolanosterol \\
\hline S031 & Ergosta-5,7,22,24(24(1))-tetraen-3- $\beta$-ol \\
\hline S032 & Ergosterol \\
\hline S033 & Isofucosterol \\
\hline S034 & Lanosterol \\
\hline S035 & Lathosterol \\
\hline S036 & Obtusifoliol \\
\hline S037 & 24-Methylenelophenol \\
\hline S038 & Stigmasterol \\
\hline S039 & Zymosterol \\
\hline
\end{tabular}


Comparative box-and-whisker plots for S-, $\mathrm{H}$ - and M-steroids for the 64 desciptors analyzed.
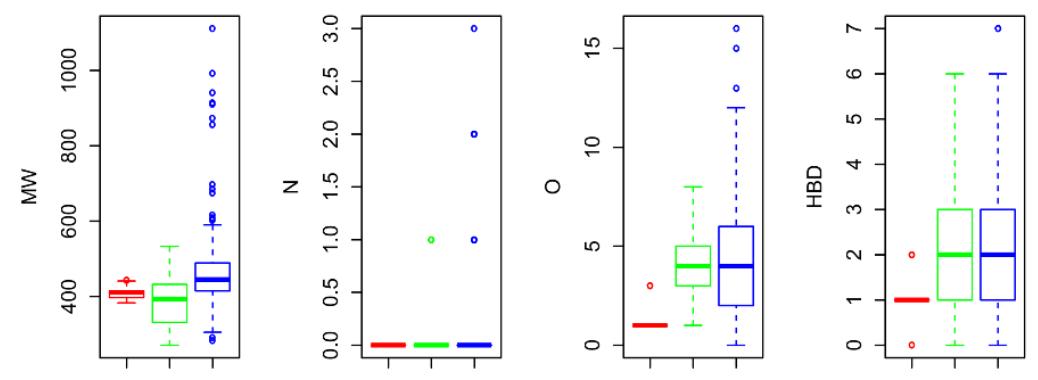

S $\mathrm{H} \quad \mathrm{M}$

S $\quad \mathrm{H} \quad \mathrm{M}$

$S \quad H \quad M$

$S \quad H \quad M$
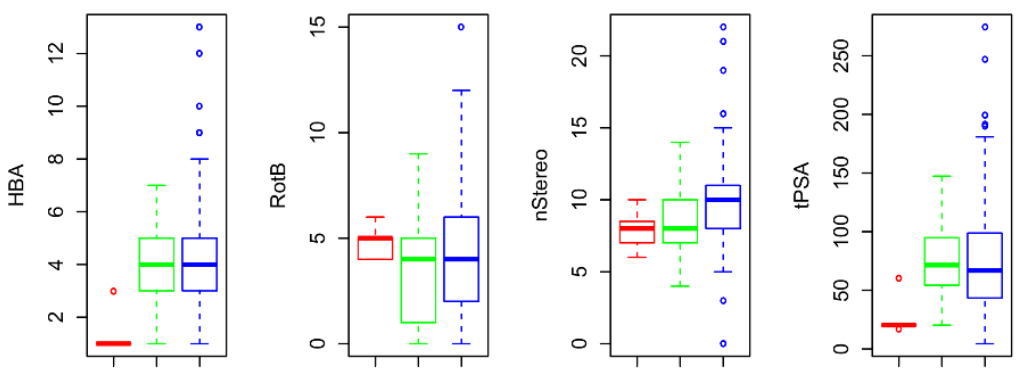

S $\mathrm{H} \quad \mathrm{M}$

S $\mathrm{H} \quad \mathrm{M}$

S $\mathrm{H} M$

S $\mathrm{H} \mathrm{M}$
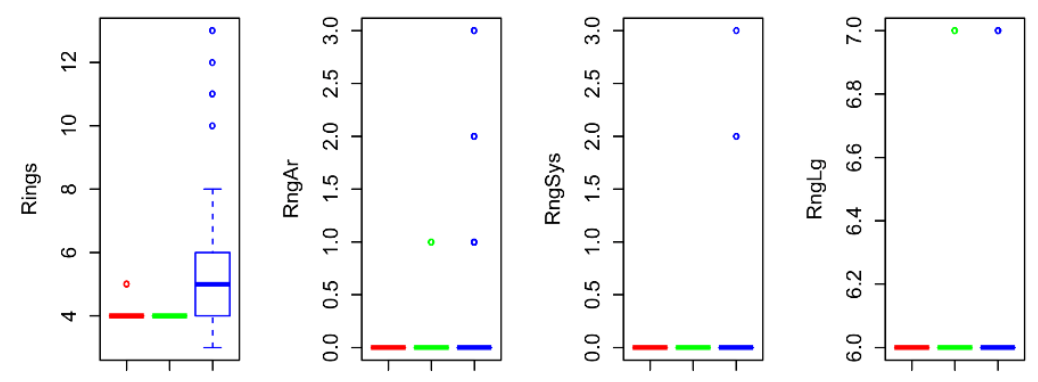

S $\mathrm{H} \mathrm{M}$

S $\mathrm{H} \quad \mathrm{M}$

S $\mathrm{H} \quad \mathrm{M}$

S $\mathrm{H} \quad \mathrm{M}$
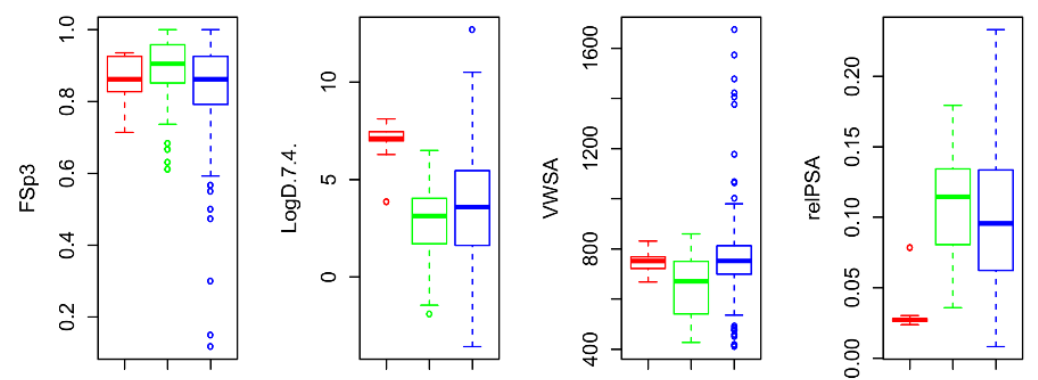

S $\mathrm{H} \quad \mathrm{M}$

S $\mathrm{H} \quad \mathrm{M}$

S $\mathrm{H} \quad \mathrm{M}$

S $\mathrm{H} \quad \mathrm{M}$ 

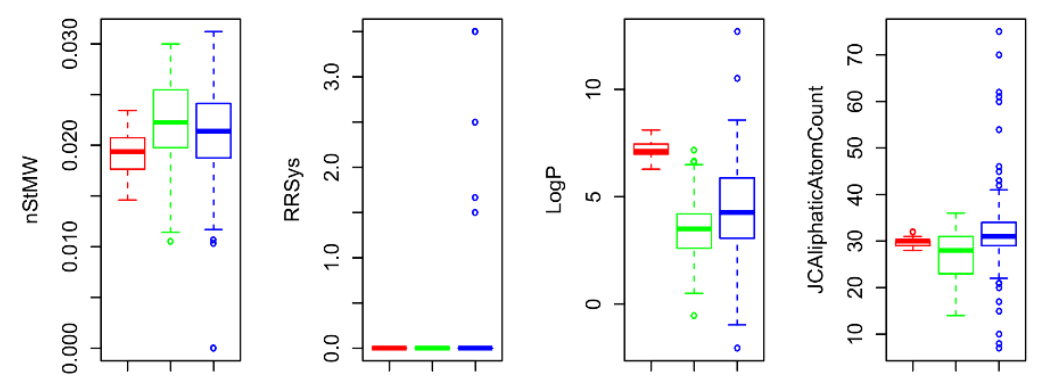

$S \mathrm{H} \mathrm{M}$

S $\mathrm{H} \mathrm{M}$

S $\mathrm{H} \mathrm{M}$

S $\mathrm{H} \mathrm{M}$
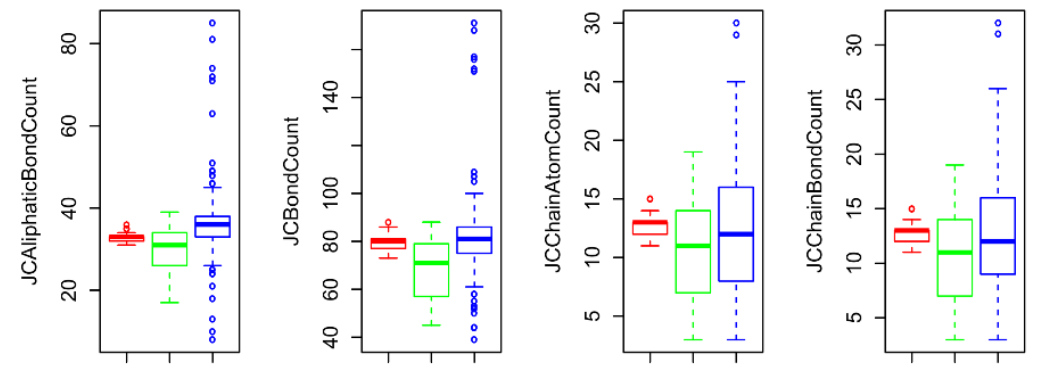

S $H \quad M$

S H M

$S H \quad M$

S H M
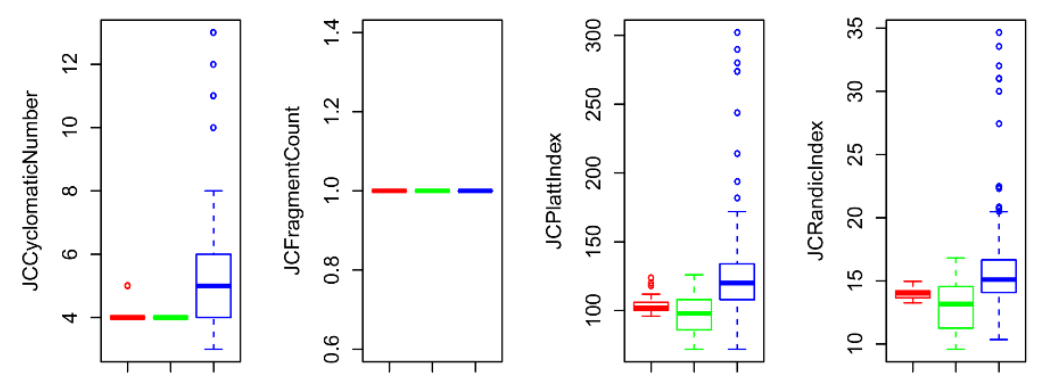

S $H \quad M$

$S H \quad M$

S $\mathrm{H} \mathrm{M}$

S $H \quad M$
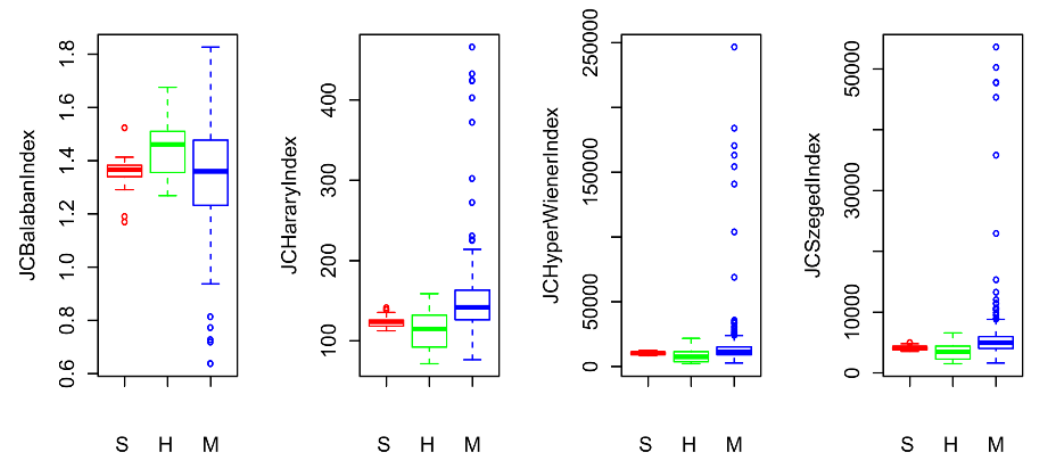

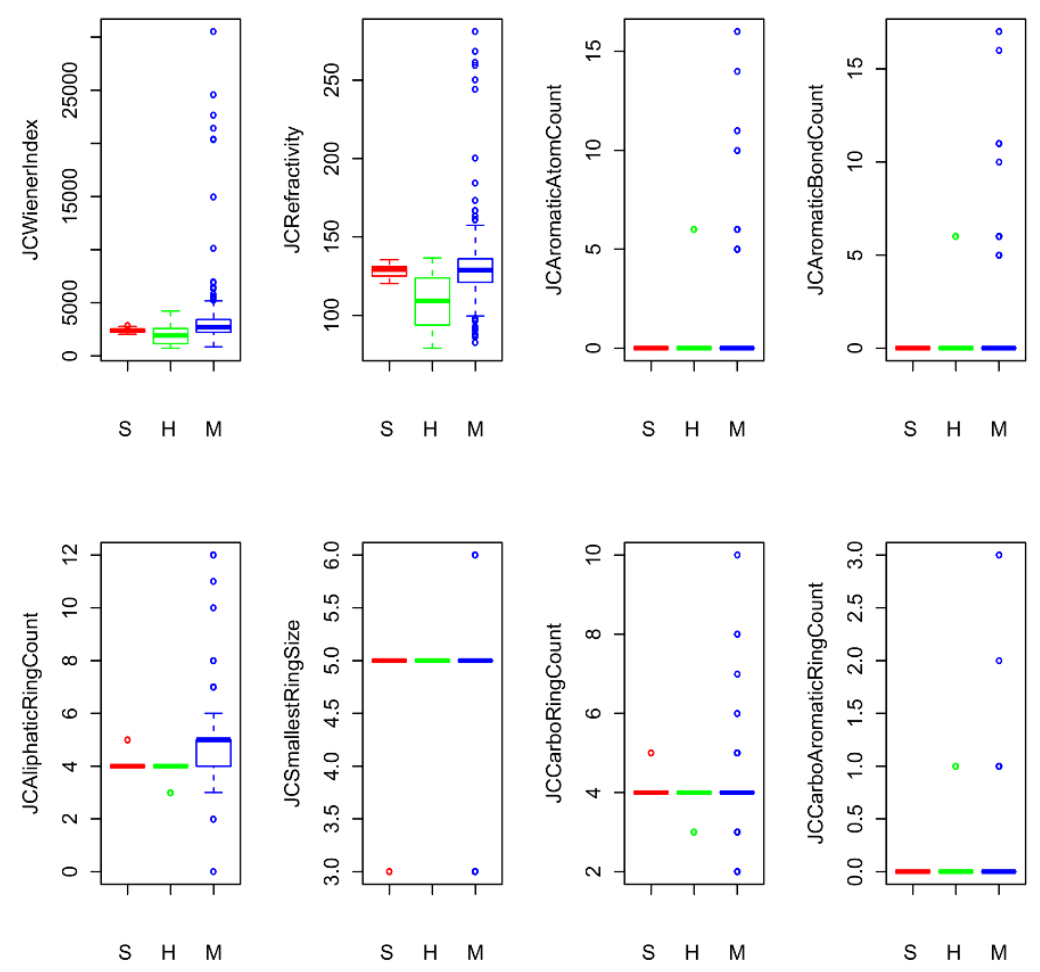

S $\mathrm{H} \quad \mathrm{M}$

S $\mathrm{H} \quad \mathrm{M}$

S $\mathrm{H} M$

S $\mathrm{H} \quad \mathrm{M}$
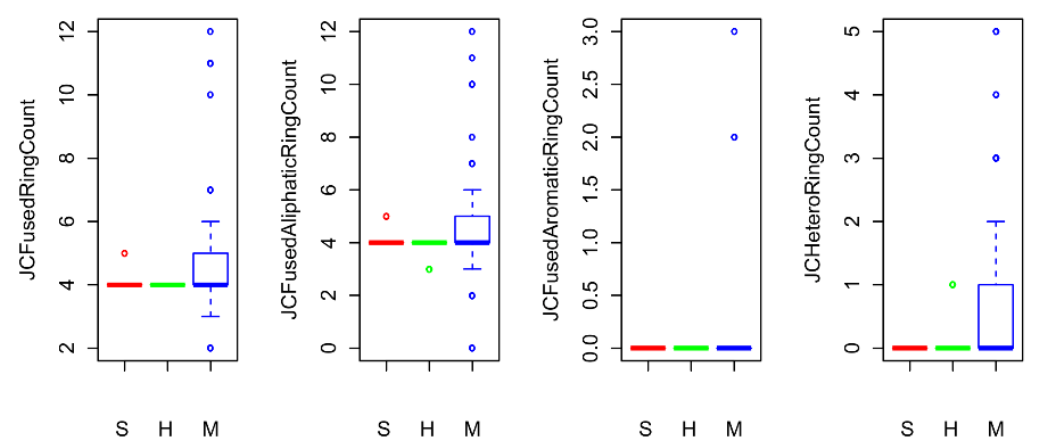

S $\mathrm{H} \quad \mathrm{M}$

S $\mathrm{H} \quad \mathrm{M}$

S $\mathrm{H} \quad \mathrm{M}$

S $\mathrm{H} \mathrm{M}$
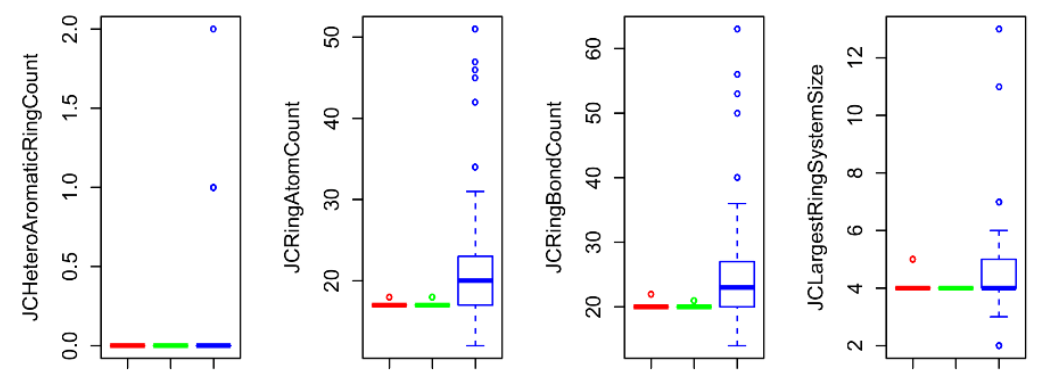

S $\mathrm{H} \quad \mathrm{M}$

S $\mathrm{H} M$

S $\mathrm{H} M$

S $\mathrm{H} \quad \mathrm{M}$ 

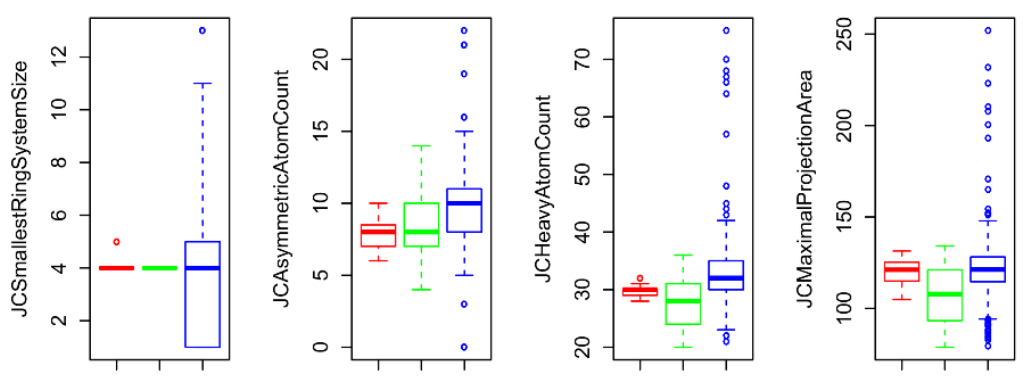

S $\mathrm{H} \quad \mathrm{M}$

S $\mathrm{H} M$

S $\mathrm{H} \quad \mathrm{M}$

S $\mathrm{H} \quad \mathrm{M}$
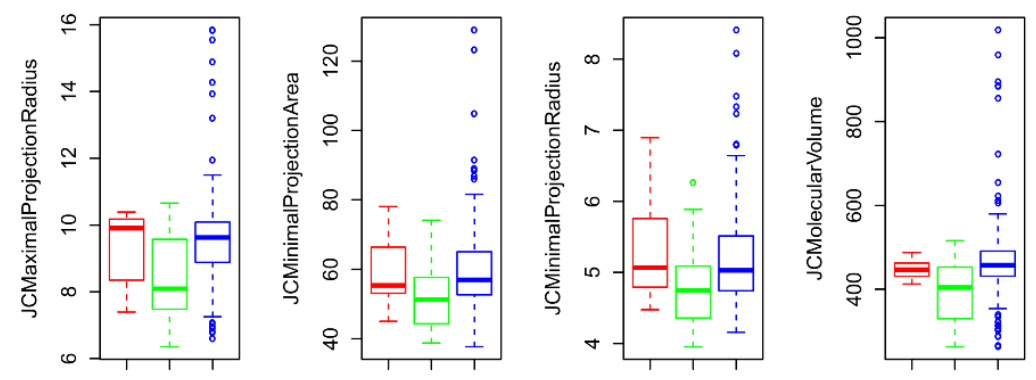

S $\mathrm{H} \mathrm{M}$

S $\mathrm{H} M$

S $\mathrm{H} M$

S $\mathrm{H} \mathrm{M}$
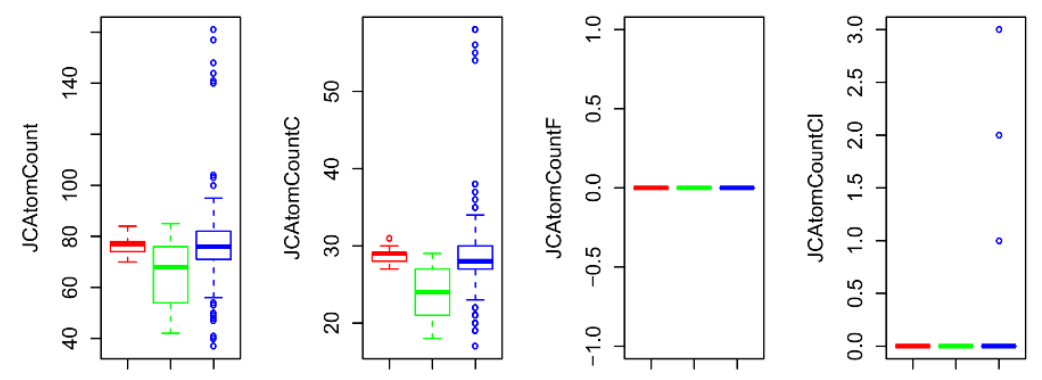

S $\mathrm{H} \quad \mathrm{M}$

S $\mathrm{H} \quad \mathrm{M}$

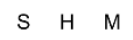

S $\mathrm{H} \quad \mathrm{M}$
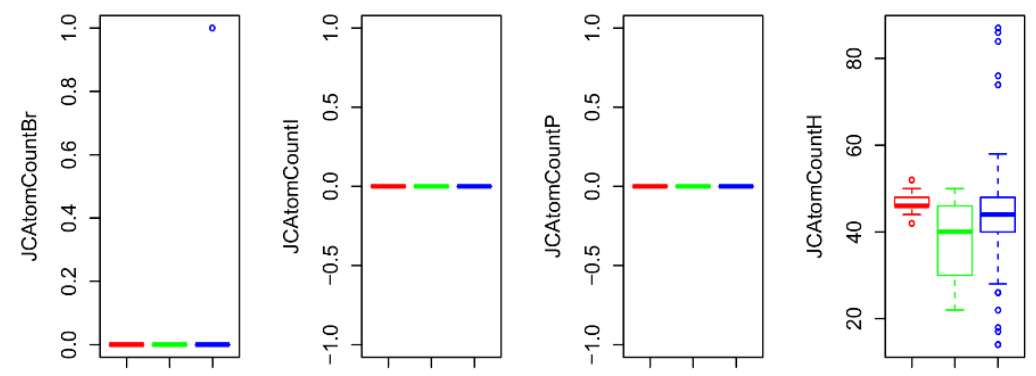

S $\mathrm{H} \mathrm{M}$

S $\mathrm{H} \quad \mathrm{M}$

S $\mathrm{H} \quad \mathrm{M}$

S $\mathrm{H} M$ 
Contribution of $\mathbf{3 0}$ variables to the main four principal components (Dim 1 to 4).

Contribution of variables to Dim-1

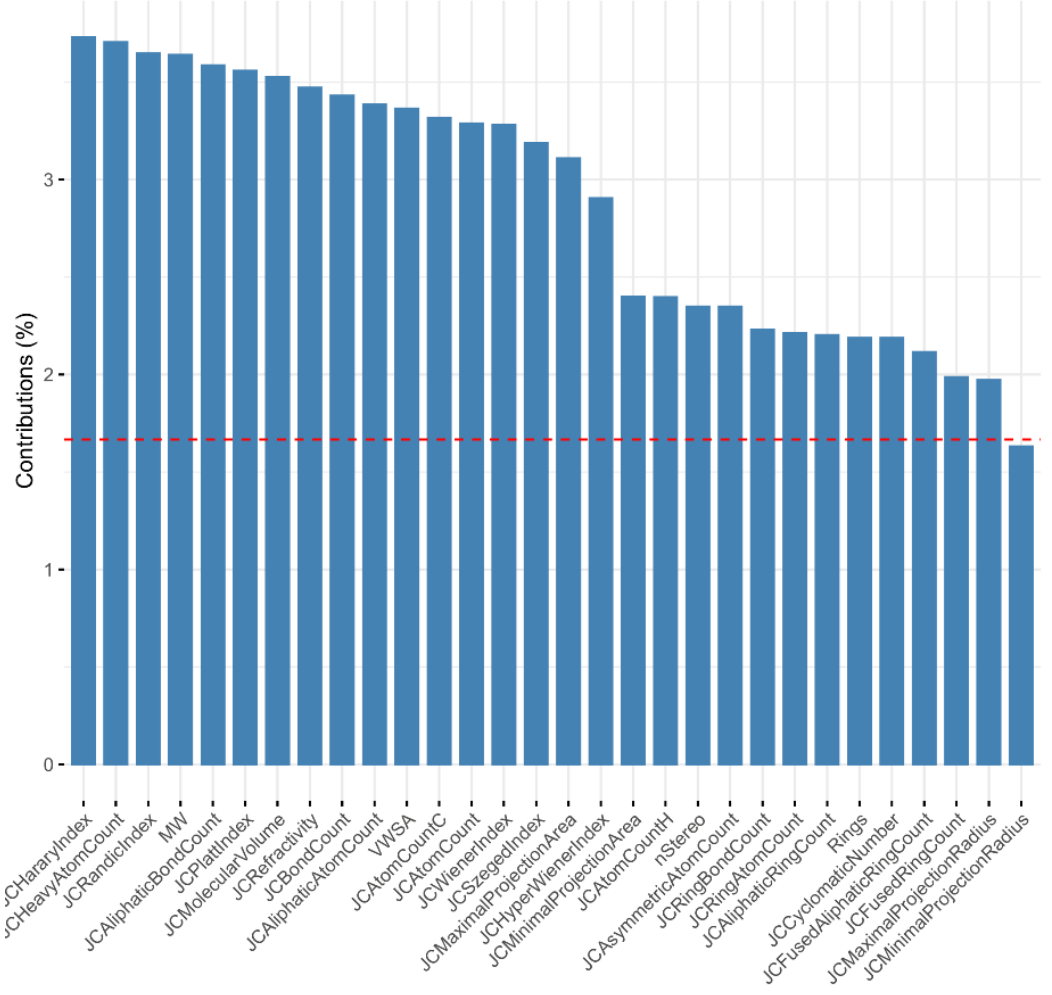

Contribution of variables to Dim-2

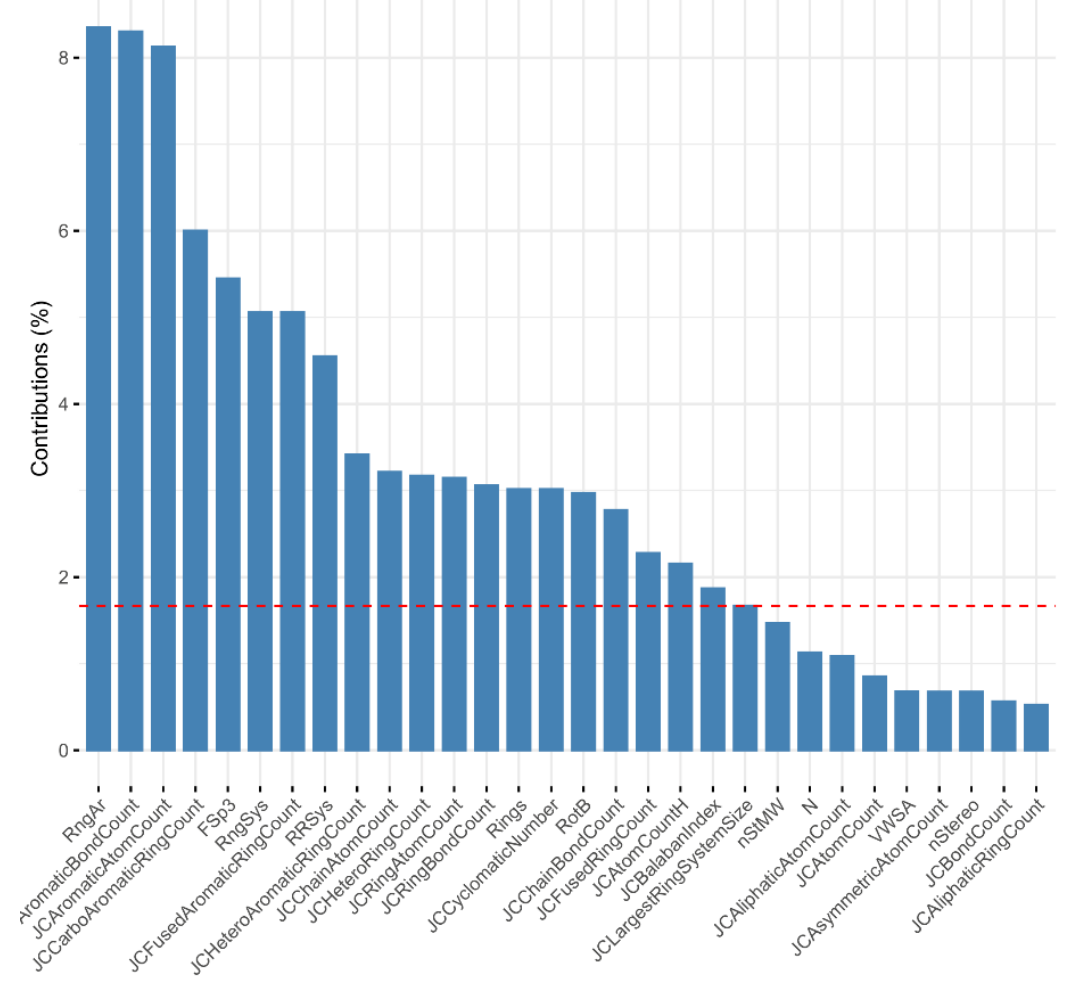




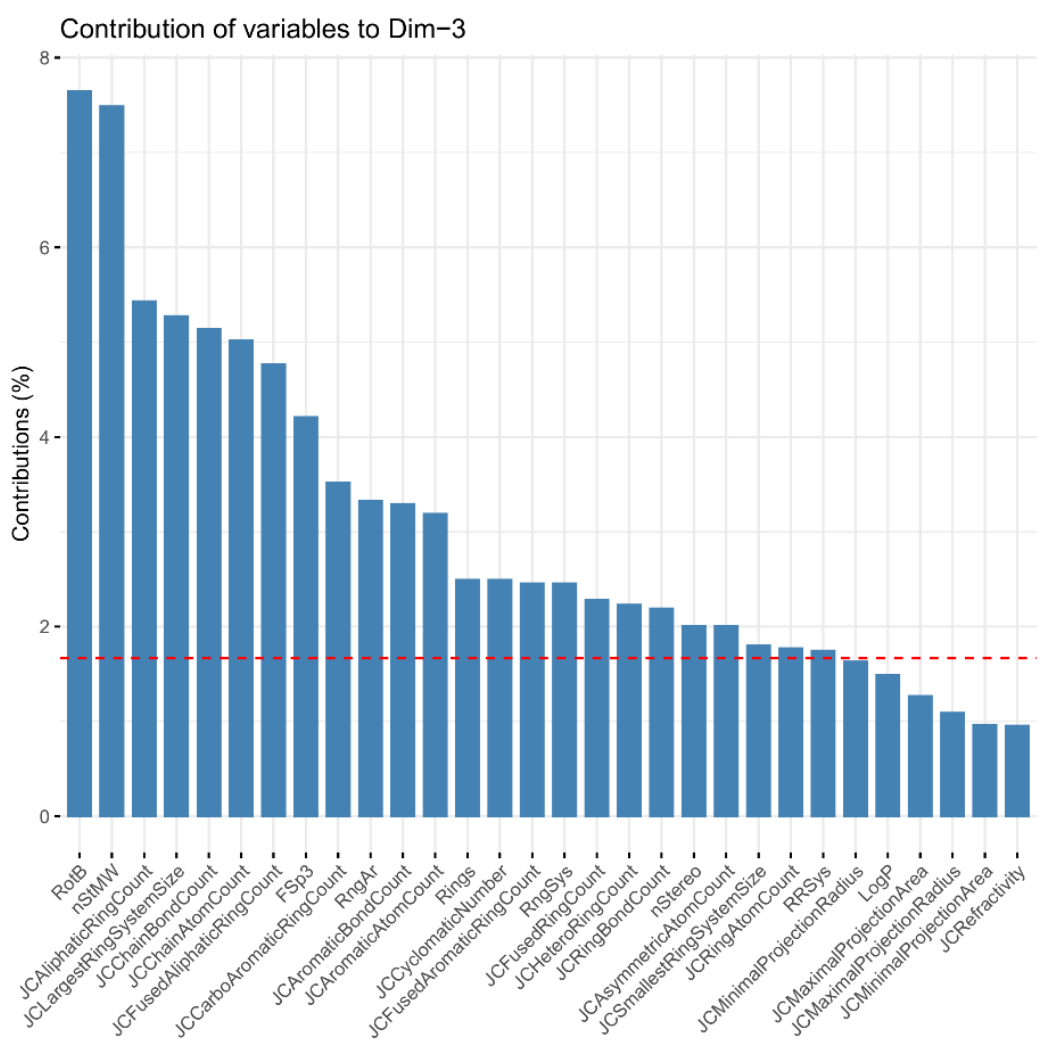

Contribution of variables to Dim-4

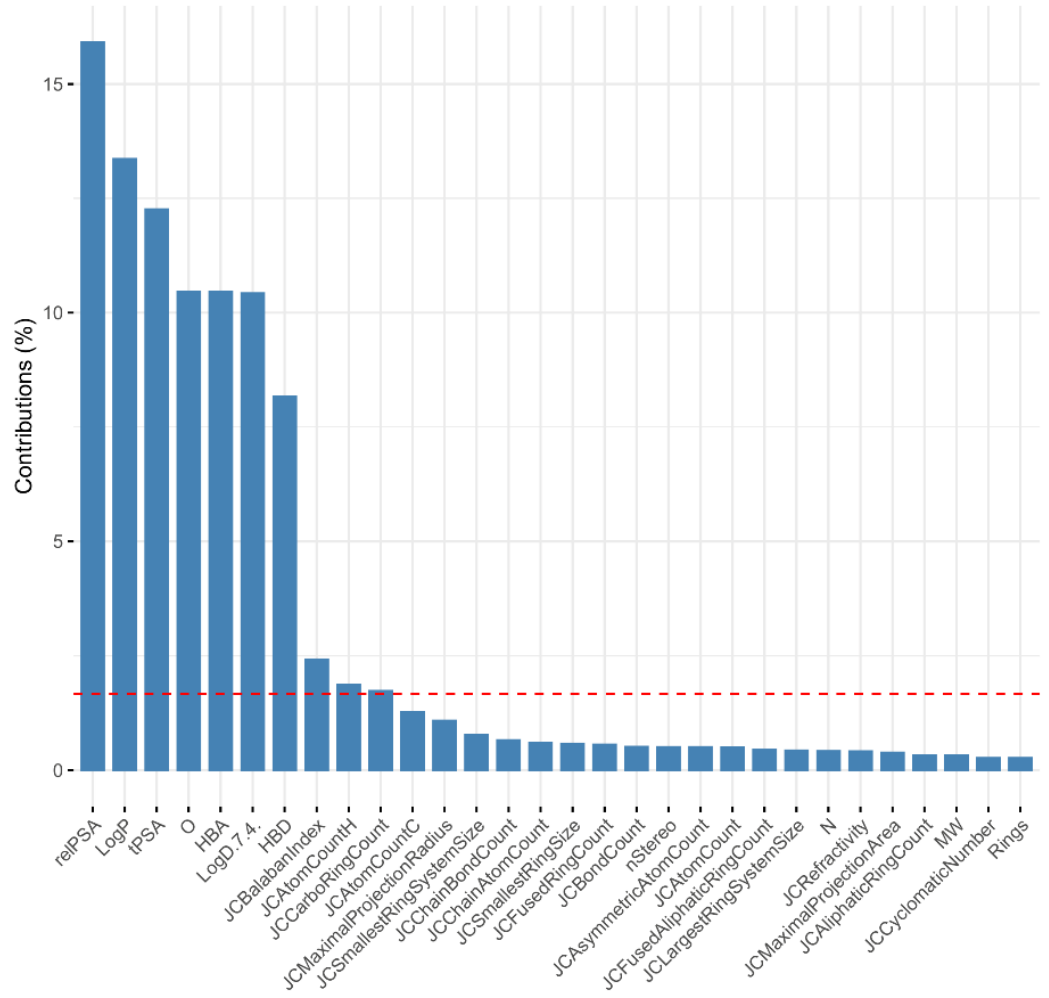


Scree plot for the first 10 principal components.

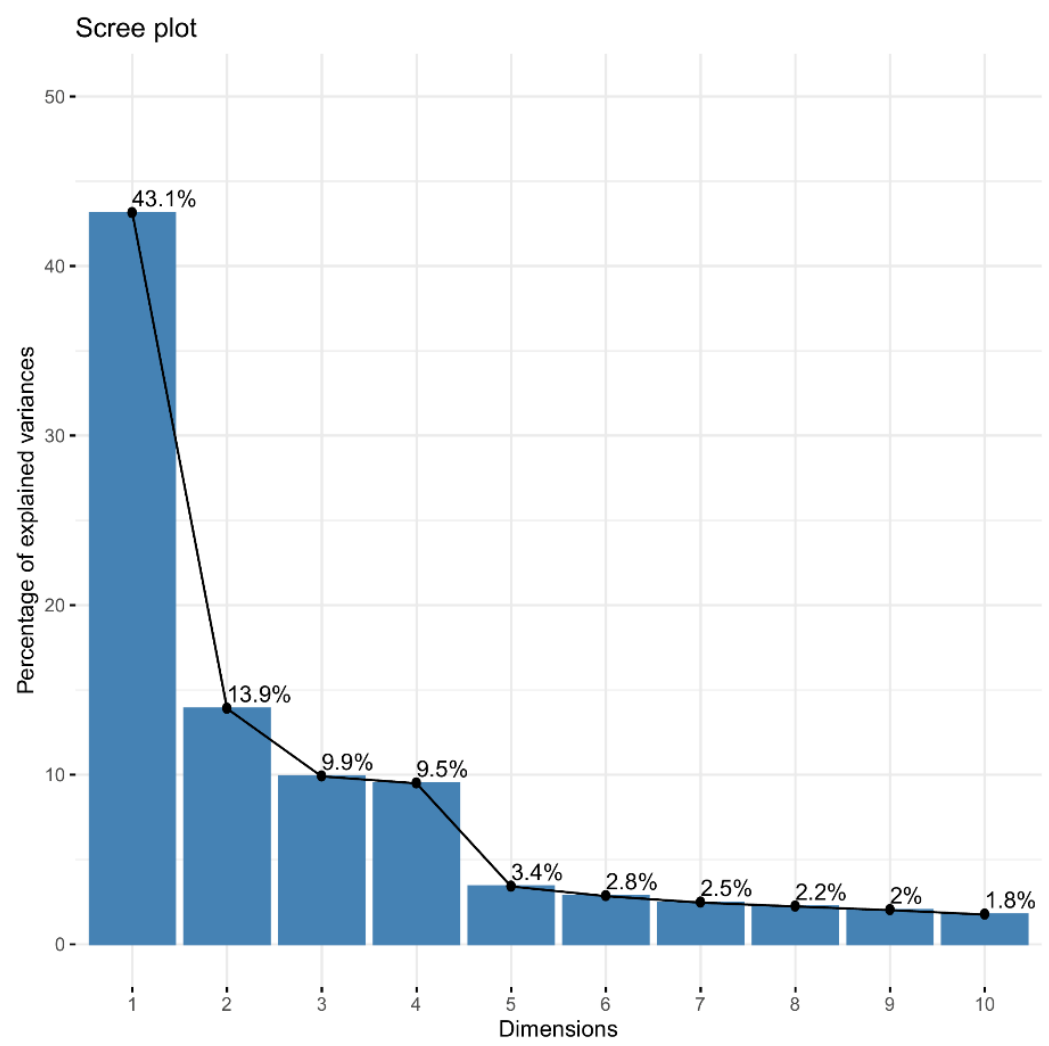

